\title{
Crater Growth and Lava-Lake Dynamics Revealed Through Multitemporal Terrestrial Lidar Scanning at Killauea Volcano, Hawai'i
}

Chapter $\mathrm{C}$ of

The 2008-2018 Summit Lava Lake at Kỉlauea Volcano, Hawai'i

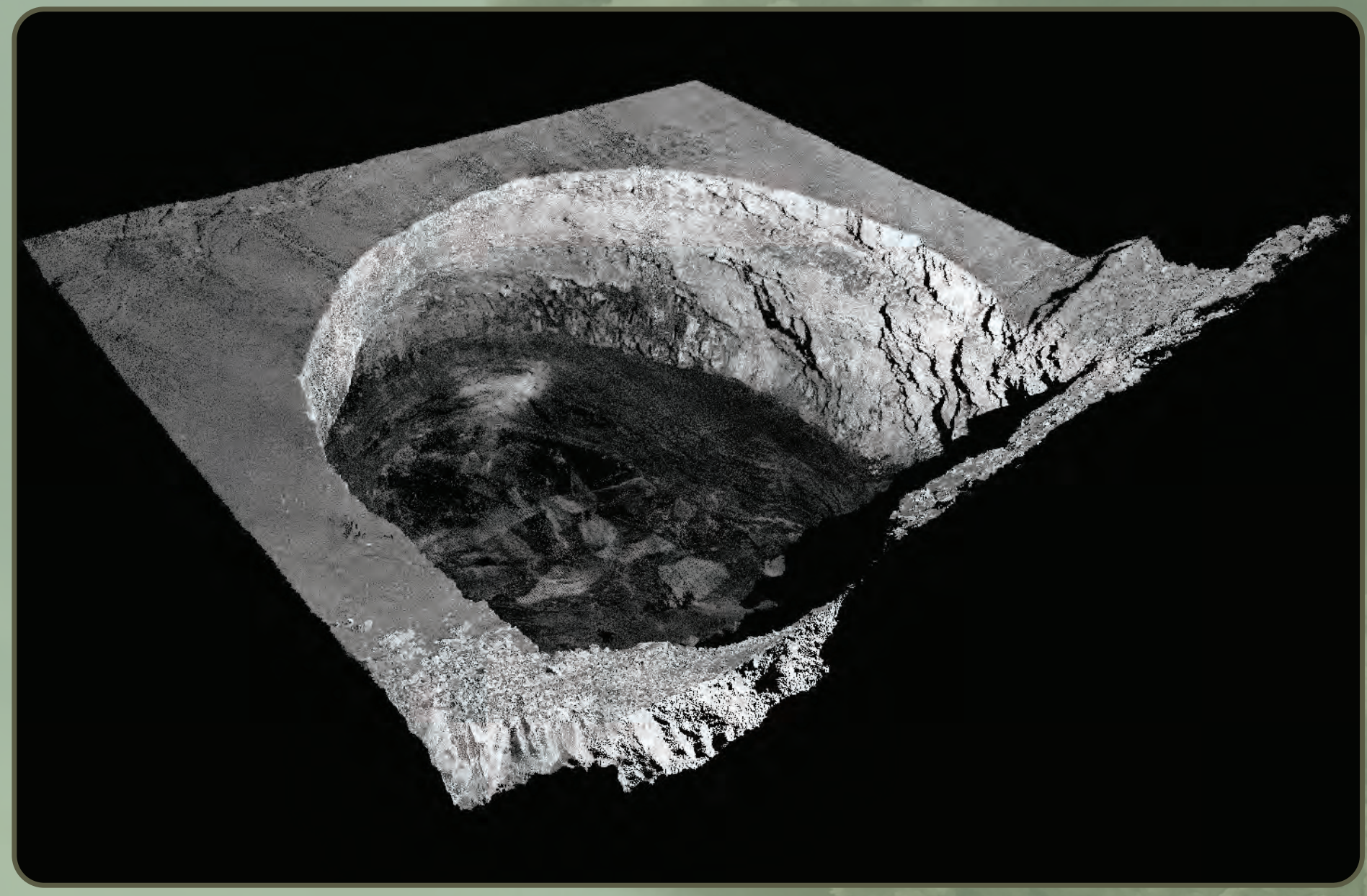

Professional Paper 1867

U.S. Department of the Interior U.S. Geological Survey 
Cover. Lidar point cloud of the Overlook crater, Kïlauea Volcano, Hawai i, from February 28, 2012, colored by reflectance. The lava level on this date was the lowest of all terrestrial laser scanning survey dates, exposing more crater wall than was seen on other dates. 


\section{Crater Growth and Lava-Lake Dynamics Revealed Through Multitemporal Terrestrial Lidar Scanning at Kïlauea Volcano, Hawai'i}

By Adam L. LeWinter, Steve W. Anderson, David C. Finnegan, Matthew R. Patrick, and Tim R. Orr

Chapter $\mathrm{C}$ of

The 2008-2018 Summit Lava Lake at Kīlauea Volcano, Hawai'i

Edited by Matthew Patrick, Tim Orr, Don Swanson, and Bruce Houghton

Professional Paper 1867

U.S. Department of the Interior

U.S. Geological Survey 


\section{U.S. Geological Survey, Reston, Virginia: 2021}

For more information on the USGS—-the Federal source for science about the Earth, its natural and living resources, natural hazards, and the environment-visit https://www.usgs.gov or call 1-888-ASK-USGS.

For an overview of USGS information products, including maps, imagery, and publications, visit https://store.usgs.gov.

Any use of trade, firm, or product names is for descriptive purposes only and does not imply endorsement by the U.S. Government.

Although this information product, for the most part, is in the public domain, it also may contain copyrighted materials as noted in the text. Permission to reproduce copyrighted items must be secured from the copyright owner.

Suggested citation:

LeWinter, A.L., Anderson, S.W., Finnegan, D.C., Patrick, M.R., and Orr, T.R., 2021, Crater growth and lava-lake dynamics revealed through multitemporal terrestrial lidar scanning at Kīlauea Volcano, Hawai'i, chap. C of Patrick, M., Orr, T., Swanson, D., and Houghton, B., eds., The 2008-2018 summit lava lake at Kïlauea Volcano, Hawai'i: U.S. Geological Survey Professional Paper 1867, 26 p., https://doi.org/10.3133/pp1867C.

ISSN 1044-9612 (print)

ISSN 2330-7102 (online) 


\section{Acknowledgments}

We thank the U.S. Geological Survey (USGS) Hawaiian Volcano Observatory for logistical support for this study and the University of Hawai'i at Mānoa Pacific GPS Facility for their 2009 and 2010 lidar data. The study was conducted as part of the USGS's monitoring of eruptive activity, and we credit Hawai'i Volcanoes National Park for facilitating this work.

We also thank the University of Northern Colorado for travel support for A.L. LeWinter and S.W. Anderson. The USGS Jack Kleinman fellowship provided A. LeWinter with additional funds to complete this study. Michael Zoeller and Glyn Williams-Jones provided thorough reviews that greatly improved the manuscript. 


\section{Contents}

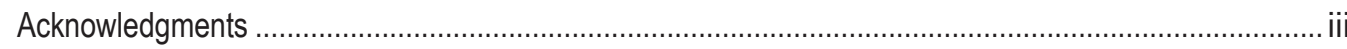

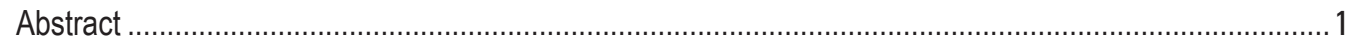

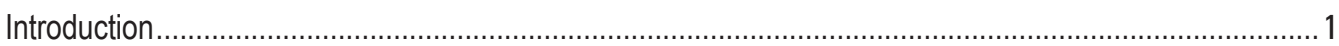

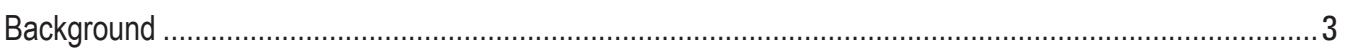

1823-1924 Lava Lake Eruptive Activity ...............................................................................

2008-2018 Activity.........................

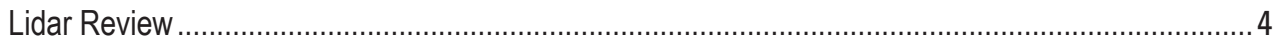

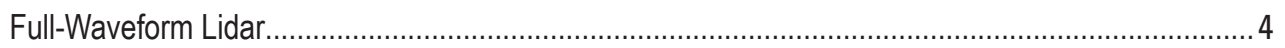

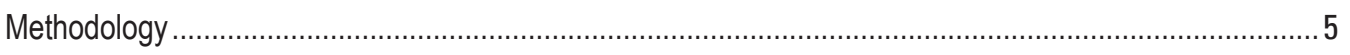

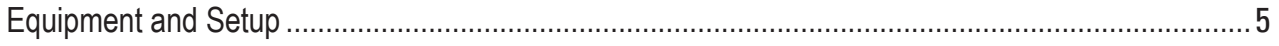

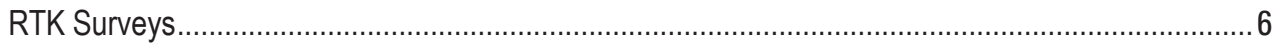

Scanning Procedure for the 2012-2013 RIEGL TLS Datasets...................................................... 6

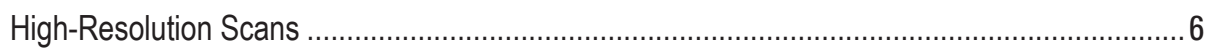

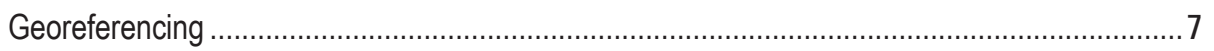

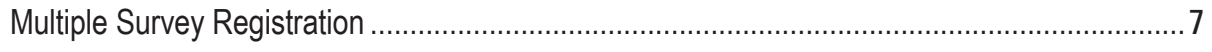

Normalizing and Reducing Lidar File Size ....................................................................

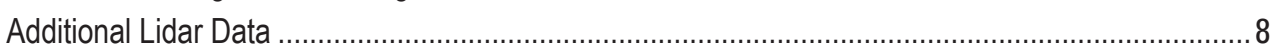

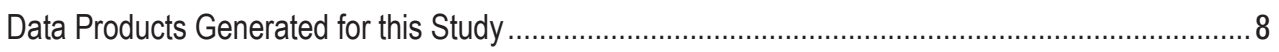

Halema'uma'u Crater Data Products .............................................................................. 8

Overlook Crater Perimeter Data Products ...................................................................... 8

Lava Lake Surface Data Products ........................................................................... 10

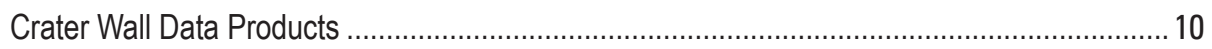

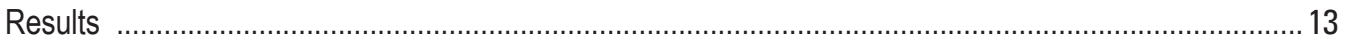

Overlook Crater Perimeter Measurement and Analysis............................................................ 13

Full Overlook Crater Perimeter and Area Measurement......................................................... 13

Partial Overlook Crater Perimeter and Area Measurement ................................................... 14

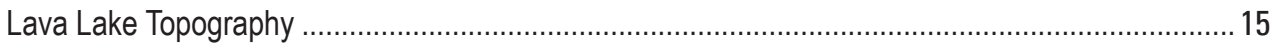

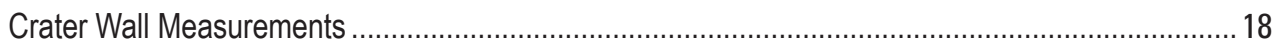

Wall Volume Change_Accretion and Degradation in the Overlook Crater ............................ 18

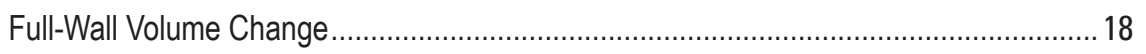

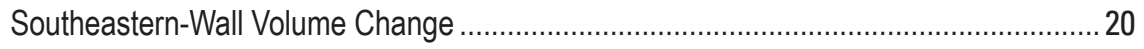

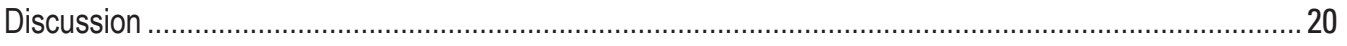

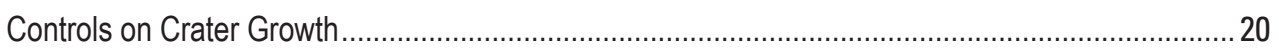

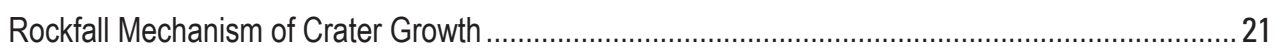

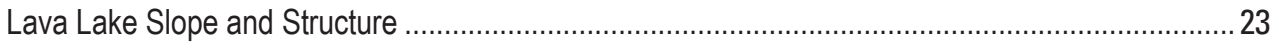

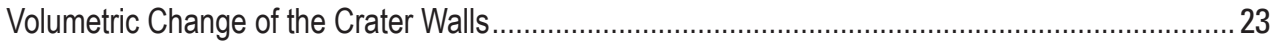

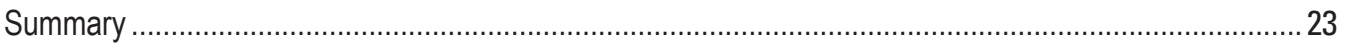

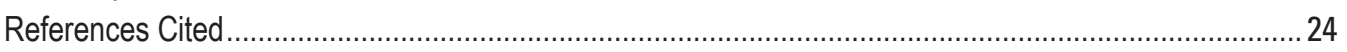




\section{Figures}

1. Maps showing the location of Kīlauea Volcano, Halema'uma'u Crater, and the 2008-18 lava lake.

2. Diagram of a full-waveform lidar setup overlaying a cross-section view of the Overlook crater 4

3. Sample images of Kîlauea Volcano, taken from the same location and perspective

4. Nadir view of a digital elevation model of the Halema'uma'u Crater, showing scanner positions, reflector locations, and the real-time kinematic base rover location at the installed benchmark from the January 14 to 15,2013 , surveys.

5. Photographic diagram of the real-time kinematic rover receiver mounted to the top of the scanner and camera

6. Images of full-density lidar point-cloud data compared to normalized data. 8

7. Nadir view images of the lidar point cloud of Halema'uma'u Crater and the Overlook crater from January 14,2013 , colored by reflectance and normalized using a 0.1 -meter octree filter...

8. Nadir view images of the lidar point cloud of the Overlook crater from January 14, 2013, colored by reflectance, illustrating the selection process for the partial-wall data

9. Images of the lidar point cloud of the Overlook crater from August 6, 2013, colored by reflectance, illustrating the selection process for the full-perimeter data

10. Image of the lidar point cloud from January 14,2013 , colored by reflectance, viewed from approximately above the Halema'uma'u Overlook, looking down into the Overlook crater....... 10

11. Images of the Overlook crater lava lake showing surface dynamics..... .11

12. Images of the lidar point cloud of the Overlook crater from February 28, 2012, showing the lava at the lowest level of all terrestrial laser scanning survey dates......

13. Images of the lidar point cloud of the Overlook crater from February 28, 2012, showing overhanging walls obstructing interior wall surfaces within the crater from nadir views.....

14. Images showing the partial-wall lidar point cloud of the Overlook crater illustrating the unrolling and rotation process using CloudCompare software

15. Plot of the Overlook crater rim using full-perimeter analysis

16. Plot of the Overlook crater perimeter length through time from the full-perimeter analysis....... 14

17. Plot of the Overlook crater opening area through time.....

18. Plot of the Overlook crater rim using partial-perimeter analysis for 7 of the 14 terrestrial laser scanning surveys compared to the partial perimeter of the same area derived from the June 27, 2009, NCALM airborne lidar survey.....

19. Plot of Overlook crater perimeter length through time from the partial-perimeter analysis........ 15

20. Images comparing the lava lake surface and height on four measurement dates .................. 17

21. Image showing the lidar point cloud of the Overlook crater from December 16, 2013, comparing the rim of the crater to rim on June 27, 2009

22. Images of surface meshes derived from the partial-wall lidar point-clouds of the Overlook crater wall, colored by reflectance, showing the volumes and areas of accretion and degradation between successive surveys .

23. Images of the partial Overlook crater wall showing accretion.

24. Series of thermal images during three consecutive Overlook crater rim collapse events from January 15 to 16,2013 


\section{Tables}

1. Overlook crater full-perimeter length and area on survey dates that had full coverage of the crater walls.

2. Overlook crater partial-perimeter length and area for all survey dates.................................. 15

3. Lava lake surface elevation measurements for both the northwest and southeast sites........... 16

4. Overlook crater full-wall degradation and accretion volumes between successive surveys...... 18

5. Record of rockfall events within the Overlook crater ........................................................ 21

6. Number of collapse events and the increase in area of the Overlook crater opening in periods between terrestrial laser scanning surveys

\section{Conversion Factors}

International System of Units to U.S. customary units

\begin{tabular}{|c|c|c|}
\hline Multiply & By & To obtain \\
\hline \multicolumn{3}{|c|}{ Length } \\
\hline centimeter $(\mathrm{cm})$ & 0.3937 & inch (in.) \\
\hline millimeter $(\mathrm{mm})$ & 0.03937 & inch (in.) \\
\hline nanometer (nm) & 0.00000003937 & inch (in.) \\
\hline meter $(\mathrm{m})$ & 3.281 & foot $(\mathrm{ft})$ \\
\hline kilometer $(\mathrm{km})$ & 0.6214 & mile (mi) \\
\hline meter $(\mathrm{m})$ & 1.094 & yard $(y d)$ \\
\hline \multicolumn{3}{|c|}{ Area } \\
\hline square meter $\left(\mathrm{m}^{2}\right)$ & 10.76 & square foot $\left(\mathrm{ft}^{2}\right)$ \\
\hline square meter $\left(\mathrm{m}^{2}\right)$ & 0.0002471 & acre \\
\hline \multicolumn{3}{|c|}{ Volume } \\
\hline cubic meter $\left(\mathrm{m}^{3}\right)$ & 264.2 & gallon (gal) \\
\hline cubic meter $\left(\mathrm{m}^{3}\right)$ & 0.0002642 & million gallons (Mgal) \\
\hline cubic meter $\left(\mathrm{m}^{3}\right)$ & 35.31 & cubic foot $\left(\mathrm{ft}^{3}\right)$ \\
\hline cubic meter $\left(\mathrm{m}^{3}\right)$ & 1.308 & cubic yard $\left(\mathrm{yd}^{3}\right)$ \\
\hline cubic meter $\left(\mathrm{m}^{3}\right)$ & 0.0008107 & acre-foot (acre-ft) \\
\hline
\end{tabular}

Temperature in degrees Celsius $\left({ }^{\circ} \mathrm{C}\right)$ may be converted to degrees Fahrenheit $\left({ }^{\circ} \mathrm{F}\right)$ as follows:

$$
{ }^{\circ} \mathrm{F}=\left(1.8 \times{ }^{\circ} \mathrm{C}\right)+32 \text {. }
$$




\section{Abbreviations}

\begin{tabular}{|c|c|}
\hline $2 \mathrm{D}$ & two dimensional \\
\hline $3 D$ & three dimensional \\
\hline a.s.l. & above sea level \\
\hline $\mathrm{cm}$ & centimeter \\
\hline $\mathrm{cm} / \mathrm{yr}$ & centimeters per year \\
\hline DEM & digital elevation model \\
\hline ERZ & East Rift Zone \\
\hline GPS & Global Positioning System \\
\hline HST & Hawaii standard time \\
\hline HVO & Hawaiian Volcano Observatory \\
\hline $\mathrm{IR}$ & infrared \\
\hline $\mathrm{km}$ & kilometer \\
\hline lidar & light detection and ranging \\
\hline $\mathrm{m}$ & meter \\
\hline $\mathrm{m} / \mathrm{yr}$ & meters per year \\
\hline$m^{2}$ & square meter \\
\hline $\mathrm{m}^{2} / \mathrm{yr}$ & square meters per year \\
\hline $\mathrm{m}^{3}$ & cubic meter \\
\hline $\mathrm{MHz}$ & megahertz \\
\hline $\mathrm{mm}$ & millimeter \\
\hline mrad & milliradian \\
\hline NCALM & National Center for Airborne Laser Mapping \\
\hline $\mathrm{nm}$ & nanometer \\
\hline OPUS & online positioning user service \\
\hline RTK & real-time kinematic \\
\hline TLS & terrestrial laser scanning \\
\hline USGS & U.S. Geological Survey \\
\hline UTM & Universal Transverse Mercator \\
\hline
\end{tabular}





\title{
Crater Growth and Lava-Lake Dynamics Revealed Through Multitemporal Terrestrial Lidar Scanning at Kïlauea Volcano, Hawai' $i$
}

\author{
By Adam L. LeWinter, ${ }^{1}$ Steve W. Anderson, ${ }^{2}$ David C. Finnegan, ${ }^{1}$ Matthew R. Patrick, ${ }^{3}$ and Tim R. Orr ${ }^{3}$
}

\begin{abstract}
Lava lake surfaces display the tops of active magma columns and respond to eruption variables such as magmatic pressure, convection, degassing, and cooling, as well as interactions with the craters that contain them. However, they are challenging to study owing to the numerous hazards that accompany these eruptions, and they are typically difficult to observe because the emitted gas plumes obscure the lava lake surfaces. The 2008-2018 Overlook crater and lava lake at Kīlauea Volcano, Hawai ‘i, provided a remarkable opportunity to study several high-resolution data streams of eruption variables that impacted the lava lake. To investigate how the crater and associated lava lake responded to changes in these eruption variables, we acquired terrestrial light detection and ranging (lidar) surveys of the Overlook crater and lava lake surface from February 2012 through December 2013, supplemented with several earlier terrestrial and airborne lidar datasets, to quantitatively track changes in the shape of the lava lake surface and the crater walls. Lidar captures highresolution data even when the lake is completely obscured by thick gas plumes. We used a novel "unrolling technique" to map volumetric changes in crater shape, because standard elevation differencing fails to capture all topographic changes on the nearly vertical, and sometimes overhanging, crater walls. We measured crater perimeter growth rates of approximately 52 meters per year from 2009 to 2013, with the greatest growth occurring along a line linking areas of persistent upwelling and downwelling. We suggest that the development of an oblong crater with a perimeter that grows linearly is best explained by a model where degradation is favored at the sites of persistent upwelling and downwelling and where growth is controlled by a lithology that varies little with respect to rock strength. We also found that most of the Overlook crater growth occurred during a relatively small number of significant rockfall events $(\sim 16)$ over this period. Additional lidar datasets revealed that the lava lake surface has a measurable slope from the areas of persistent upwelling to downwelling, although rockfalls from the crater walls
\end{abstract}

${ }^{1}$ U.S. Army Corps of Engineers.

${ }^{2}$ University of Northern Colorado.

${ }^{3}$ U.S. Geological Survey. temporarily changed the direction of crustal plate movement along with the magnitude and direction of the lava lake surface slope. Our study demonstrates that lidar is an effective tool for tracking the topography of an active volcanic crater when heavy outgassing renders other tools, such as structure from motion, ineffective.

\section{Introduction}

Active lava lakes provide insights into eruption processes by exposing the surfaces of convecting, open-vent magmatic systems (Patrick and others, 2016; Lopes and others, 2018; Burzynski and others, 2018; Valade and others, 2018). As of early 2018, there were 10 persistently active lava lakes on Earth (Lopes and others, 2018), with their respective volcanoes presenting hazards that could impact millions of people annually. For example, the 1977 and 2002 fissure eruptions that catastrophically drained the lava lake at Nyiragongo volcano (Democratic Republic of the Congo) killed 70 and 147 people, respectively (Demant and others, 1994; Allard and others, 2002). In addition, from 2008 to 2018 a lava lake formed at Kīlauea Volcano, Hawai' $i$, within Hawai'i Volcanoes National Park, a popular tourist area that had more than 2 million visitors in 2018 (Thomas and Koonce, 2019). High $\mathrm{SO}_{2}$ levels and particulates, coming primarily from this summit lava lake, were responsible for the closure of parts of the park out of safety concerns (Elias and Sutton, 2017; Elias and others, 2018) and created health concerns for downwind residents (Longo, 2013; Tam and others, 2016; Elias and others, 2018). The new crater containing this lava lake, later informally named the "Overlook crater" because of its position below the Halema'uma'u Overlook, enlarged substantially from 2008 to 2018 as the crater walls collapsed. Most of these rockfalls impacted the lava lake, and some triggered explosions that tossed lithic and juvenile material onto the surrounding caldera floor (Wilson and others, 2008; Orr and others, 2013), creating hazardous conditions for scientists in the field.

The Overlook crater and lava lake initially formed on March 19, 2008, when an approximately 35-meter (m)-wide vent opened along the southeastern wall of the 1-kilometer (km)-wide Halema'uma'u Crater (Patrick and others, 2019a) (fig. 1). Because of its proximity to the U.S. Geological Survey (USGS) Hawaiian Volcano Observatory (HVO), the Overlook 

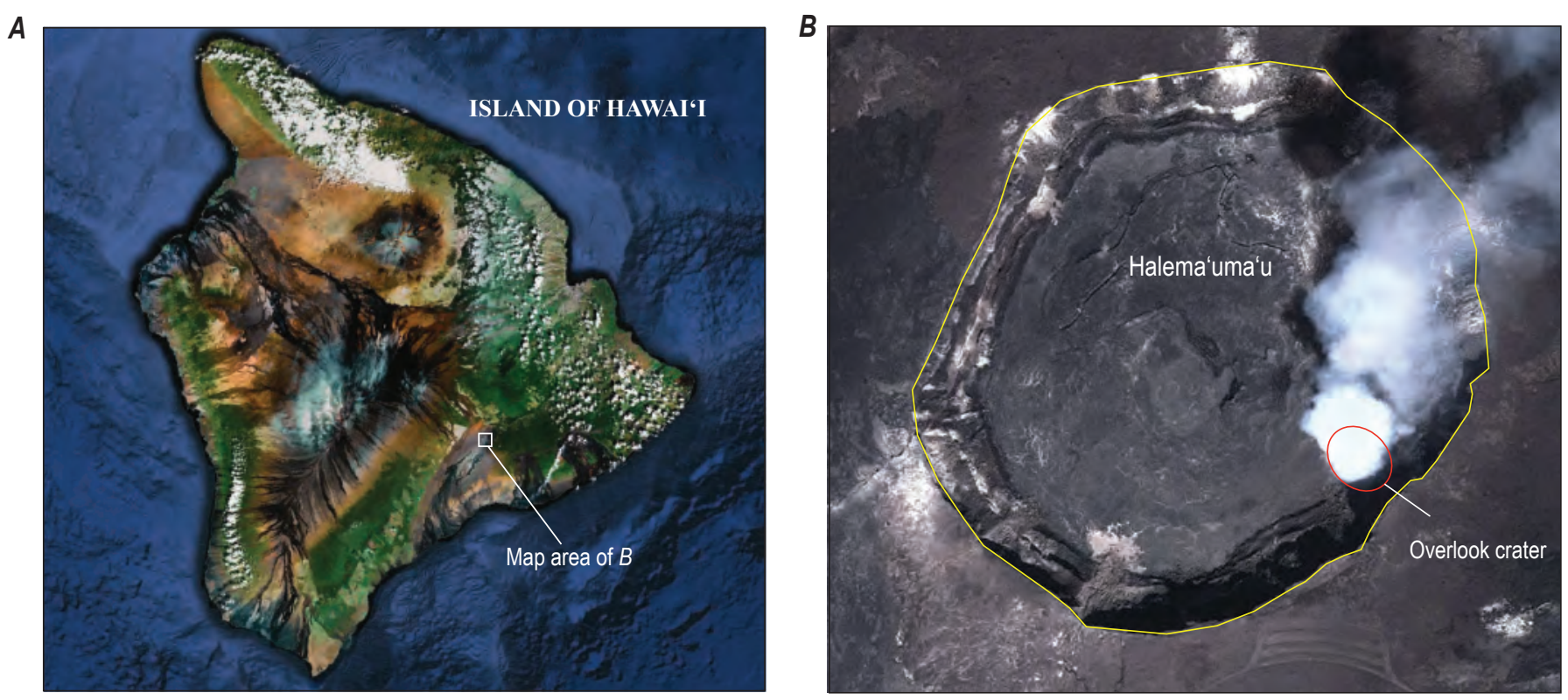

Figure 1. Maps showing the location of Kīlauea Volcano, Halema'uma'u Crater, and the 2008-18 lava lake. $A$, The Island of Hawai'i in the Pacific Ocean with Halema'uma'u Crater, prior to mid-2018, approximated by the white box. B, Halema'uma'u Crater (yellow outline), at $\sim 1$ kilometer diameter and $\sim 80$ meters deep, situated within the Kïlauea summit caldera. The Overlook crater (red outline) contained an active lava lake and was adjacent to the southeastern wall of Halema'uma'u Crater.

crater and lava-lake system provided a unique opportunity to obtain several long-term data streams that provide insight regarding the formation and evolution of the lava lake and its enclosing pit crater, forming a scientific foundation for mitigating hazards.

In addition, understanding lava lake eruption processes may provide insights regarding the magma supply (Oppenheimer and others, 2009) and the connectivity between the summit and downrift activity (Orr and others, 2015). For example, during 2011 the Kamoamoa fissure eruption along the Kîlauea East Rift Zone (ERZ) effused lava for 7 days, corresponding with a rapid drop in lava level within the Overlook crater (Orr and others, 2015). In 1924, the rapid draining of the summit lava lake at Kîlauea resulted in subsidence of Halema'uma' $u$ Crater and a series of explosive eruptions spread over 18 days (Decker and Christiansen, 1984; Mastin and others, 1999).

Lava lakes are hazardous locations, requiring that fieldbased studies such as topographic surveys occur from a safe distance. Terrestrial laser scanning (TLS) using light detection and ranging (lidar) technology provides highly accurate and precise (subcentimeter) topography, while reducing risk to researchers because these instruments can be used at standoff distances ranging from several hundred meters to several kilometers.

Until recently, lidar measurements were limited to a single returned range measurement per laser pulse (Glennie and others, 2013). The result of this limitation, when attempting to measure through gas and ash plumes common at active lava lakes, was that many of the laser pulses interacted with particles in the plume rather than the lake surface or crater walls. With the introduction of full-waveform analysis, a technique that provides multiple topographic measurements from a single pulse, it is now possible to "see through" the volcanic plume by using the last return, effectively filtering out earlier returns caused by interaction with material in the plume (fig. 2 of Glennie and others, 2013; LeWinter, 2014).

To quantitatively track the evolution of the Overlook crater and gain insight regarding the processes that control its growth, we conducted several TLS surveys from February 2012 through December 2013 and supplemented these with earlier TLS and airborne lidar datasets. Through competing processes of accretion and degradation caused by fluctuations in the lava level, outgassing activity from the lake, and weakening of the crater wall rock leading to collapse, the once nearly circular Overlook crater enlarged from an initial diameter of about $35 \mathrm{~m}$ in March 2008 to its December 2013 oblong shape with major and minor axis lengths of approximately 212 and $171 \mathrm{~m}$, respectively. Specifically, the main topics we address include:

1. The development of a methodology for multitemporal, high-resolution ground-based TLS data acquisition and processing in environments where ash, lithic particles, steam, and gas emissions have historically hampered topographic data-collection efforts.

2. The use of lidar data to quantify the Overlook crater perimeter growth rate. We then compare these results with past research concerning the growth of active lava lakes and craters.

3. The development of a methodology to use lidar data to quantify volumetric accretion and degradation changes between survey dates. This includes a discussion about the locations of accretion and 
degradation within the Overlook crater, whether or not accretion deposits persist, and the calculation of a volumetric growth rate within the crater.

4. The relation among lava-level fluctuations, lake surface convection regimes, and Overlook crater growth. Particularly, does a higher lava level accelerate crater wall collapse, as a result of increased contact with magma and greater thermal expansion and contraction along the crater walls? Do areas of upwelling and downflow correspond to unique features in the lake shape?

Many studies that employ topographic differencing rely on quantifying changes in altitude $(z)$ at each point on a horizontal plane $(x y)$. Those methods do not work for quantifying the growth of a cylindrical crater where accretion and degradation may occur in any horizontal or vertical plane, especially where the crater undercuts its rim. Here we used a novel "unrolling technique" to map volumetric changes in crater shape, applicable to a variety of complex landscape evaluation projects for rapid acquisition and processing of lidar data where standard differencing fails to capture all topographic changes.

\section{Background}

Kîlauea is a basaltic volcano, erupting tholeiitic basalt with an extrusion temperature of approximately 1,150 to 1,225 degrees Celsius $\left({ }^{\circ} \mathrm{C}\right)$ (Williams and McBirney, 1979). Two rift zones propagate outward from the summit of Kinlauea Volcano: the ERZ and the Southwest Rift Zone. Volcanic activity has occurred at the summit and along these rift zones (Okubo and Martel, 1998). $\mathrm{Pu}^{\prime} \mathrm{u}$ ' $\overline{\mathrm{O}}^{`} \overline{\mathrm{o}}$, a vent along the ERZ, was active from 1983 to 2018, producing the most voluminous eruption during the past five centuries (Dzurisin and Poland, 2018). Prior to the summer of 2018, Kîlauea Caldera measured about $4 \times 3 \mathrm{~km}$ and contained the about 1-km-diameter Halema'uma $u$ Crater, forming a nested caldera (Williams and McBirney, 1979). Within Halema'uma'u Crater was the Overlook crater and its active lava lake (Wilson and others, 2008; Patrick and others, 2018) (fig. 1).

\section{3-1924 Lava Lake Eruptive Activity}

From 1823 until 1924 there was nearly uninterrupted lava lake activity within Halema'uma'u Crater (Macdonald, 1955; Wright and Klein, 2014). Perret's (1913a-f) observations of the active lava lake in 1911 provide a useful comparison to the Overlook crater lava lake. Of note, Perret observed both persistent areas of upwelling, where fresh magma rose to the lake surface, and an area of downflow, where denser, cooled crustal plates sank into the lake as volatiles within the magma were outgassed, allowing him to hypothesize on the circulatory system within the magma column feeding the lava lake (Perret, 1913c). He noted that the lake surface was lower at the sites of outgassing, creating a sloped lake surface that caused the flow of crustal plates. In addition to the circulatory system, Perret (2013c) noticed consistent features along the cooled and solidified borders of the lava lake. He described "spatter grottoes"- sections of overhanging wall veneer bordering the area of downflow, formed by spatter ejection from outgassing bursts.

Perret (1913c) also hypothesized on the shape of lava lakes and their containing craters as activity fluctuates. He suggested that normal conditions on the surface of the lava lake, characterized by consistent upwelling, crustal plate motion, and downflow, would produce an oblong lake with the areas of upwelling and downflow at opposite ends of the long axis. Sub-normal activity is defined by slow crustal plate movement, accentuating the oblong shape of the lake as the surface magma cools and adheres to the walls bordering the lake parallel to crustal plate flow. Finally, super-normal activity is characterized by faster crustal plate movement, producing a more circular lava lake as consolidation of rock along the crater walls is impeded and re-melting occurs (Perret, 1913c).

Beginning in February 1924, following increased seismic activity at Kilauea's summit and along the ERZ, the summit lava lake drained out of view, and the floor of Halema 'uma' $u$ Crater gradually subsided until it was $200 \mathrm{~m}$ below the Halema'uma'u Crater rim by May 6, 1924 (Decker and Christiansen, 1984). During this time, parts of the Halema' uma' $u$ Crater walls collapsed into the crater, and on May 10, 1924, a series of explosions began. Over the next 17 days, hundreds of blasts ejected lithic debris from Halema'uma'u Crater ranging in size from small ash particles to an 8-ton block (Mastin and others, 1999), resulting in one fatality.

\section{8-2018 Activity}

On March 19, 2008, an explosive eruption accompanied the opening of a $35-\mathrm{m}$-wide crater along the southeastern wall of Halema'uma'u Crater, following increased seismic activity and volatile emissions that began in November 2007 (Wilson and others, 2008). The initial Overlook crater vent widened over the following years, mainly owing to sporadic collapse of its walls, to approximately $172 \times 212 \mathrm{~m}$ by December 16 , 2013. Lava within the Overlook crater was clearly visible beginning on September 5, 2008, followed by a period of transient lava lake activity through early 2010 (Patrick and others, 2021). Continuous lava lake activity began in February 2010 and continued through May 2018 (Patrick and others, 2021). Between February 2010 and December 2013, the period of this study, the lava level was as high as $22 \mathrm{~m}$ and as low as $210 \mathrm{~m}$ below the Halema'uma'u Crater floor.

Patrick and others (2019a) suggested that medium- to long-term changes (hours to months) in lava levels were pressure driven and tied to episodic inflation and deflation of the summit region, whereas short-term changes (seconds to hours) resulted from outgassing processes near the lake surface. Lava rose as pressure in the underlying summit magma reservoir increased, and its level fell when reservoir pressure decreased, sometimes concurrent with eruptions along the ERZ (Patrick and others, 2015, 2019a,b). On March 5, 2011, there was rapid reservoir deflation and 
increased seismic activity observed by summit tiltmeters and seismometers (Lundgren and others, 2013; Orr and others, 2015; Patrick and others, 2019b). This correlated with deflation and collapse of the $\mathrm{Pu}^{\prime} \mathrm{u}$ ' ${ }^{\circ}{ }^{\prime} \bar{o}$ crater floor on the ERZ. Several hours later, a fissure opened $3 \mathrm{~km}$ uprift of $\mathrm{Pu}^{\prime} \mathrm{u}$ ' $\bar{O}^{`} \bar{o}$ and began erupting lava fountains, building multiple spatter cones, and feeding lava flows (Orr and others, 2015). Simultaneously, the Overlook crater lava level dropped to $210 \mathrm{~m}$ below the floor of Halema'uma'u Crater, as tracked by time-lapse cameras focused on the lake. The Kamoamoa fissure eruption lasted until March 11, 2011, after which $\mathrm{Pu}^{\text {' } \mathrm{u}}$ ${ }^{\prime} \bar{O}^{`} \bar{o}$ and the Overlook crater gradually began to refill.

\section{Lidar Review}

Lidar systems have become the standard for capturing high-resolution topography of the Earth's surface (Glennie and others, 2013). Utilizing a laser pulse, point clouds derived from millions of individual surface measurements are transposed into representative digital surface models. We focus here mostly on the use of TLS to capture multitemporal, highresolution lidar data and the use of this technique to assess changes in the geometry of the lava lake and associated crater.

Lidar systems incorporate the following components: a rapid pulse laser source, receivers for measuring backscattered radiation, a timing mechanism to precisely capture laser signal transmit and return times, and internal processors with computing capabilities for calculating range. Lidar sensors emit a laser pulse at a known time, then measure the backscattered radiation and elapsed time, resulting in a range measurement from the laser source to an object (Glennie and others, 2013). This is referred to as time-of-flight ranging and is described by the time-of-flight equation:

$$
\Delta t=2 R / c
$$

where

$$
\begin{gathered}
\Delta t \quad \begin{array}{c}
\text { is time between the laser emission and return } \\
\text { signal of backscattered radiation, }
\end{array} \\
R \quad \text { is range from the laser source and the } \\
\text { measured object, and }
\end{gathered}
$$

By precisely measuring $\Delta t$, range may be calculated using the following equation:

$$
R=(\Delta t \times c) / 2
$$

Basic lidar sensors only capture a single distance measurement. These systems are improved upon by incorporating a rotating or oscillating mirror to deflect the laser signal about an axis, creating a two-dimensional (2D) measurement plane. For ground-based TLS setups, the addition of a precision rotating stage to rotate the sensor about a second (vertical) axis results in a three-dimensional (3D) scan. By using precision angular encoders that measure both the vertical and horizontal angle for an emitted laser pulse, each measurement is in 3D space (Fowler and Kadatskiy,
2011). The resulting point cloud is therefore a collection of point measurements with $x$-, $y$-, and $z$-values in a 3D Cartesian coordinate system. These values are then projected onto a global coordinate system by associating points within the scan and scanner setup positions to known control positions.

\section{Full-Waveform Lidar}

As the lidar laser beam diverges with distance, the laser pulse forms a cone of light, with its source at the scanner, that continually expands in diameter with range. If this cone of diffraction (Mallet and Bretar, 2009) interacts with an object larger than its diameter, then a single energy pulse will return to the sensor. As the range increases, so does the cone's diameter, increasing the chance for the cone to interact with multiple objects. For example, small objects such as lithic and juvenile particles in the Halema'uma'u gas plume will interact with a portion of the emitted laser pulse, allowing the remaining energy to continue until a particle or object larger than the cone reflects the entire remaining pulse. In this manner, multiple objects at different ranges from the scanner can be measured with a single laser pulse (fig. 2), allowing lidar to effectively "see through" the plume. Recording of the entire backscattered energy within the cone of diffraction is termed full-waveform lidar (Mallet and Bretar, 2009). The emitted and returned pulses in full-waveform systems are best represented by Gaussian curves, as shown in figure 2 (Wagner and others, 2006). Figure 3 illustrates how the Halema 'uma'u plume hinders visibility but not lidar measurements.

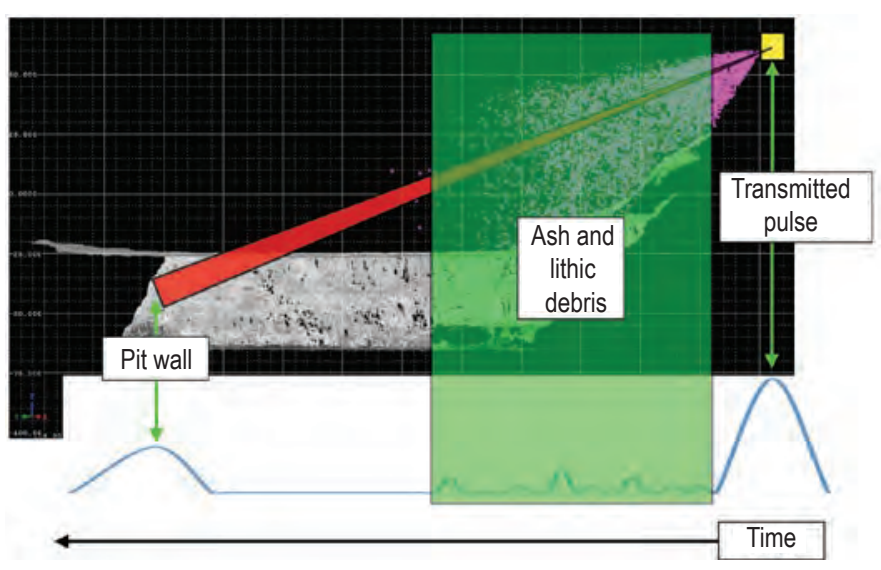

\section{EXPLANATION}

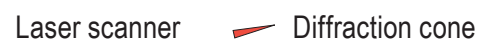

Figure 2. Diagram of a full-waveform lidar setup overlaying a crosssection view of the Overlook crater. The yellow box represents the laser scanner, with a diverging laser pulse in the form of a diffraction cone (red). A transmitted pulse is logged with measured amplitude. As the beam interacts with the volcanic plume containing gas and ash (green box), low amplitude signals are returned to the sensor. A final signal measured on the crater wall, or last return, is reflected with higher amplitude. The blue pulse is an idealized waveform, not an actual waveform from a measured pulse. 

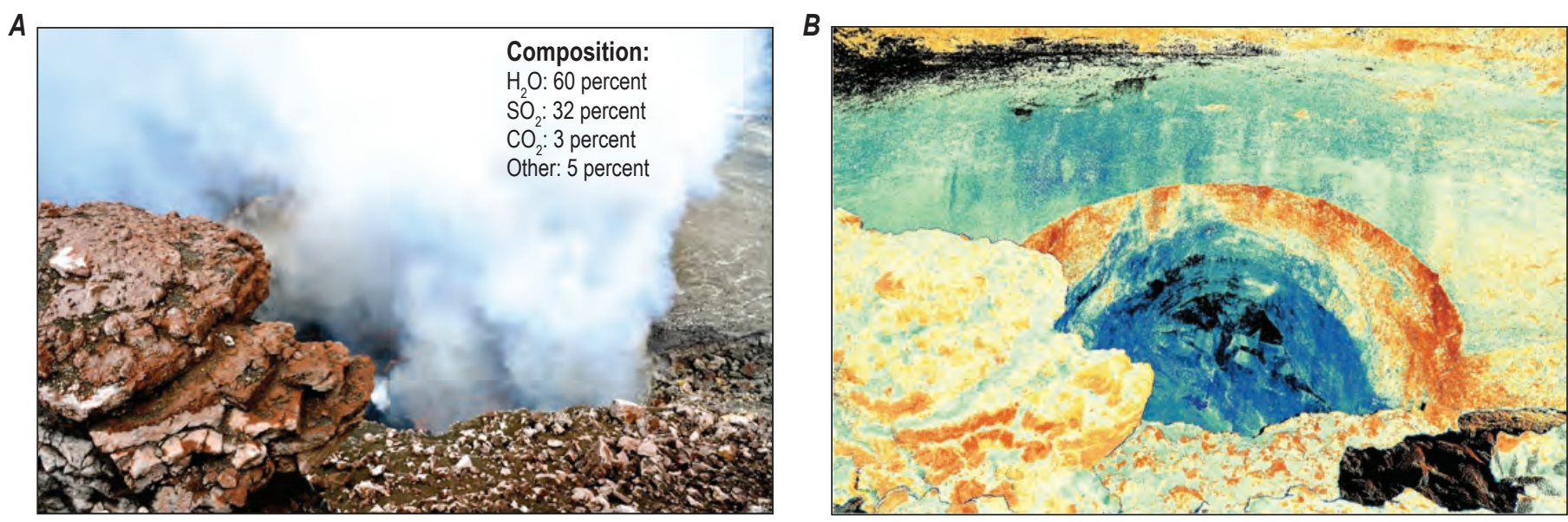

Figure 3. Sample images of Kilauea Volcano, taken from the same location and perspective. A, Digital photograph taken with a Nikon D700 camera, showing the gas plume obstructing visibility into the Overlook crater. $B$, Image showing point cloud colored by intensity (blue-to-red scale shows low-to-high intensity). The crater walls and lava lake are fully imaged using waveform processing.

Various factors contribute to measurement error when using lidar scanners, including instrument capabilities and calibration, atmospheric interaction, target properties, and measurement geometry (Kaasalainen and others, 2011). LeWinter (2014) provides a detailed discussion of potential lidar errors.

\section{Methodology}

We acquired 12 TLS datasets from February 2012 through December 2013, supplemented with 2 additional TLS datasets acquired by the University of Hawai' $i$ at Mānoa Pacific GPS (Global Positioning System) Facility in 2009 and 2010, and 1 airborne lidar survey from 2009, providing a total of 15 high-resolution datasets to quantitatively track the evolution of the Overlook crater. Some of these datasets capture the entire Overlook crater, others image only a partial Overlook crater perimeter owing to line-of-sight constraints, and two (August 8 and 9,2013) were used only for lava level and Overlook crater wall volume calculations. By supplementing the TLS data we collected with the lidar data collected by other groups, the temporal range of this study was increased by more than 2.5 years. Below we provide background on the technology used during data acquisition, as well as field and data processing methodology.

\section{Equipment and Setup}

To quantify changes at the Overlook crater in 2012 and 2013, we used a RIEGL VZ-1000 1,550-nanometer (nm) wavelength laser scanner with maximum accuracy and precision of 8 and 5 millimeters $(\mathrm{mm})$, respectively. The laser was set to a pulse rate of 70 megahertz (MHz), with an effective measurement rate of 29,000 measurements per second. The scanner incorporates a rotating mirror and rotating head to achieve a $360^{\circ}$ horizontal $(\varphi)$ and $100^{\circ}$ vertical $(\theta)$ field of view. With a beam divergence of 0.3 milliradian $(\mathrm{mrad})$ and a maximum range of approximately $1 \mathrm{~km}$, the maximum beam footprint at $1 \mathrm{~km}$ is 30 centimeters $(\mathrm{cm})$.

The lidar system is a portable unit, capable of being transported and operated by a team of two. We used a survey tripod to support the scanner and allow positioning of the system for optimal viewing angles, with a primary goal of providing the maximum line-of-sight coverage of the Overlook crater and lava lake. Given that the scanner has a $100^{\circ}$ vertical field of view, and that the floor of Halema 'uma 'u Crater and the Overlook crater are below the overlook scanning location (fig. 4), the sensor needed to be tilted downward to capture the crater floor and the walls (fig. 5). A tilt mount allowed for a $90^{\circ}$ tilt of the scanner below horizontal to ensure optimal area coverage. We attached a real-time kinematic (RTK) receiver (described further below) to the top of the setup to obtain precise location measurements of the scanner.

The scanner is equipped with an internal inclination sensor that actively measures the roll and pitch of the sensor. Although the inclination sensor accounts for and corrects any difference between the horizontal ( $x y$-plane) and the scanner, any tilt of the scanner will be accentuated in the RTK rover receiver position, as it is $0.35 \mathrm{~m}$ above the scanner origin. For example, a tilt of $20^{\circ}$ correlates to a horizontal offset of $0.12 \mathrm{~m}$, which would contribute to a positional error (fig. 5). We avoided this error contribution by using an in-scanner level to set up the scanner within $0.5^{\circ}$ of the horizontal plane, minimizing the horizontal offset to $3 \mathrm{~mm}$. We collected RTK measurements before tilting the scanner. 


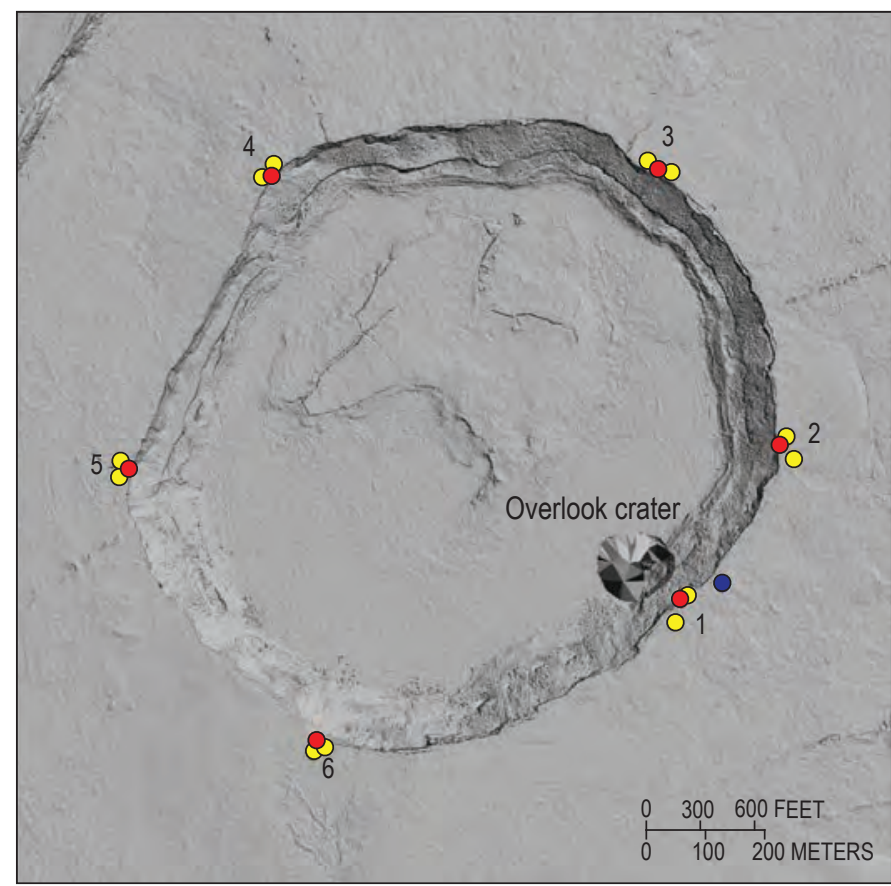

EXPLANATION

- Scanner position - Benchmark O Reflector

Figure 4. Nadir view of a digital elevation model of the Halema'uma'u Crater, showing scanner positions, reflector locations, and the real-time kinematic (RTK) base rover location at the installed benchmark from the January 14 to 15, 2013, surveys. This scan position distribution provides full coverage of Halema'uma'u Crater.

\section{RTK Surveys}

We used a Trimble R8 RTK system, with a base and rover receiver pair to log both scanner position and the position of reference reflectors, in combination with the internal inclination sensor on the scanner. We deployed two 10-cm cylinder reflectors about $20 \mathrm{~m}$ away from the scanner in different directions to provide control for tying the lidar data to the Universal Transverse Mercator (UTM) coordinate system (fig. 4). We used two reflectors in case postprocessing revealed that the coordinate collection was unsuccessful, or the reflector shifted during scanning owing to wind or other external factors.

Static processing was used for all base-station online positioning user service (OPUS) solutions. A recalculated, higher accuracy benchmark coordinate was output for the base station. OPUS solutions are best if they are submitted at least 14 days after the survey, which allows the most precise orbit to be acquired. The overall root-mean-square error value for the recalculated base station coordinate on January 15, 2013, was $1.2 \mathrm{~cm}$. Detailed procedures for registering scans to the UTM coordinate system, as well as the full OPUS solution report for January 15, 2013, are reported by LeWinter (2014).

We collected 12 TLS datasets from 2012 to 2013, of which 3 covered the entire Halema' uma' $u$ Crater and were created by merging multiple TLS scans from various positions on the Halema' uma'u Crater rim (fig. 4). Seven additional datasets were acquired from a single position above the
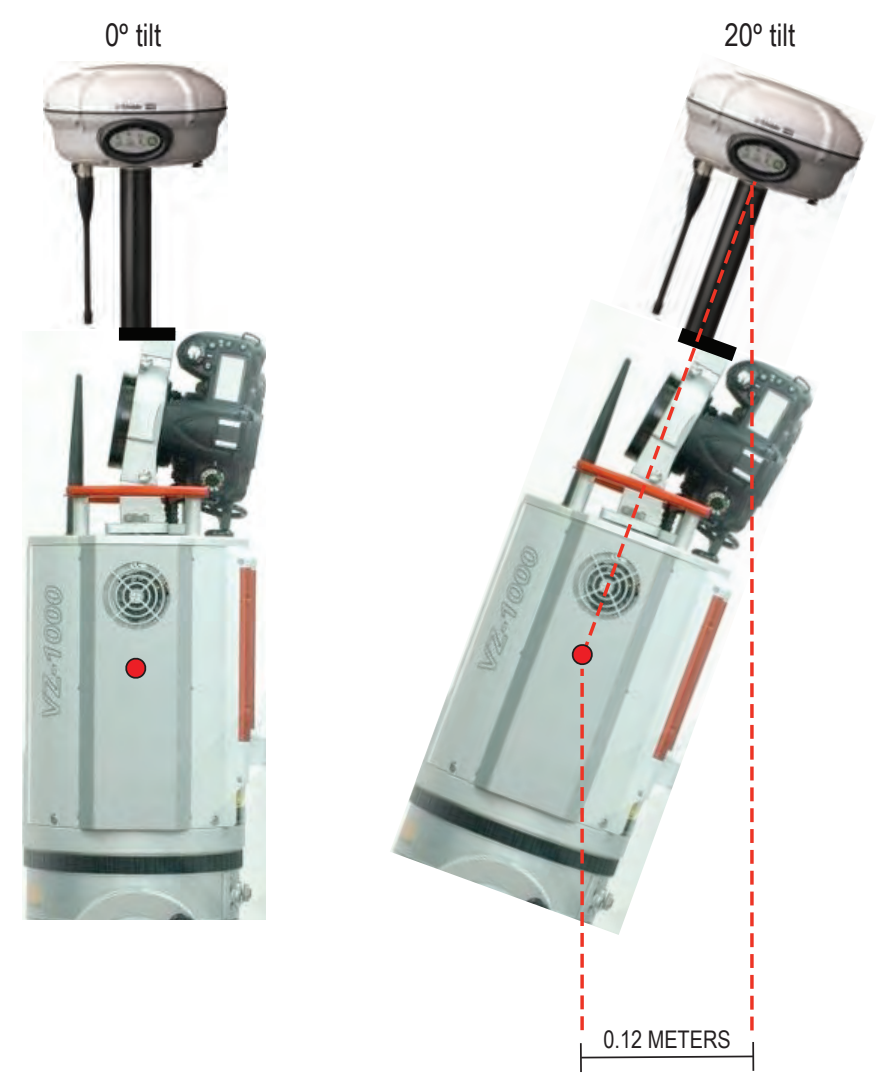

Figure 5. Photographic diagram (side view) of the real-time kinematic (RTK) rover receiver mounted to the top of the scanner and camera. Any tilt of the scanner during setup results in a horizontal offset of the measured coordinate for the scanner's origin. The right image is an example of a setup with a $20^{\circ}$ tilt, resulting in a horizontal offset of 0.12 meters.

Overlook crater. Because part of the Halema'uma'u Crater rim obscured part of the Overlook crater from this position, only part of the Overlook crater is captured in these datasets. Two additional datasets were used only to measure lava levels and wall volume changes.

\section{Scanning Procedure for the 2012-2013 RIEGL TLS Datasets}

\section{High-Resolution Scans}

The desired point density of the focus area, whether the entire Halema 'uma'u Crater or just the Overlook crater, required small angular stepwidths to resolve fine surface features. A high-resolution scan involved decreasing the angular stepwidth, while selecting the start and stop angles for both $\theta$ and $\varphi$. Typical angular stepwidths for high-resolution scans range from $0.04^{\circ}$ to $0.002^{\circ}$. Proper selection of the scan region through the $\theta$ and $\varphi$ start and stop angles allowed us to capture the highest resolution dataset possible without extraneous data that would needlessly increase file size and processing time. 
The scan position located closest to the Overlook crater (fig. 4) provided the best viewing angle of the inner crater walls and lava lake, but it lacked the line of sight needed to capture the entire crater perimeter. To select the smallest scan region possible that included all areas of interest, the scanner had to be tilted $45^{\circ}$ (fig. 5). We acquired 12 high-resolution scans of the focus area from this position and used this configuration from 2012 to 2013.

We merged six lidar scans from different positions along the rim of Halema'uma'u Crater (fig. 4) to create a single lidar dataset of the entire Halema'uma'u Crater on January 14, 2013, August 6, 2013, and December 16, 2013. Each set of these scans includes the entire perimeter of the Overlook crater. Since lidar relies on line of sight, obstructions such as ledges and scarps within the crater limited the area visible from a single scan position. Therefore, multiple scan positions were necessary to fully capture the topography of the entire Halema'uma' $u$ Crater and the Overlook crater. The National Center for Airborne Laser Mapping (NCALM) airborne lidar dataset from June 27, 2009, also shows the entire Halema'uma'u Crater, giving us high-resolution measurements of the full Overlook crater perimeter on four different dates. Figure 4 shows the distribution of scan positions, reflector locations, and RTK benchmark locations for all our lidar scans. LeWinter (2014) provides detailed instructions for combining multiple scans of a single area.

\section{Georeferencing}

Each TLS scan was tied to a global coordinate system by incorporating the RTK position data of the scanner and in-scan reflectors. We used "backsighting orientation" to incorporate the in-scanner inclination sensor with the external measurements of scanner position and cylinder reflector positions via the RTK survey. Backsighting orientation eliminates all six degrees of freedom ( $x, y, z$, yaw, pitch, and roll) and places the point cloud in its correct global position. By assigning the UTM coordinate values to the scanner's origin, $x$-, $y$-, and $z$-coordinates are set. Locating a reflector within the scan provides a compass orientation to the data, thus properly aligning the horizontal position of the scan. LeWinter (2014) provides details for accomplishing this task with RIEGL's RiSCAN PRO proprietary software (RIEGL, 2013).

\section{Multiple Survey Registration}

A detailed look at the data after georegistration revealed that the datasets for different scans were still not properly aligned for the topographic differencing needed to address our scientific questions. In addition to error introduced by the VZ-1000 and the GPS, tectonic plate movement contributed to systematic positional offset between surveys. The Hawaiian Islands are moving northwest on the Pacific Plate at approximately 5 to 10 centimeters per year (cm/yr) (Garcia and others, 2006). As the main intention of this study is to compare the change over time locally at the Overlook crater, tectonic movement and deformation are not of interest and were removed from the analysis so that the topographic datasets properly overlap.

To that end, we choose a survey tied to the UTM coordinate system to which we could align all other lidar datasets. Aligning the datasets required identification of static features that did not change in their relative positions from scan to scan. The chosen survey occurred on February 18, 2012. LeWinter (2014) provides details of the process used to align all scans used in this study for topographic differencing. We also needed to align the NCALM airborne data to this base scan. Since the NCALM data was already georeferenced, it was approximately aligned with our TLS data, but it still had positional offsets owing to sensor errors, inflation and deflation of the volcano summit, and tectonic plate movement. Additional postprocessing described by LeWinter (2014) eliminated these errors to allow a focus on local morphometric changes. In addition, 2009 and 2010 TLS data from University of Hawai'i at Mānoa Pacific GPS Facility using the OPTECH system were also aligned in the same manner.

Once the lidar datasets were collected, georeferenced, and registered to one another by identifying shared static points, derivative products were prepared to quantify our research questions: the growth of the Overlook crater (as seen by both the enlarging of its opening and the increase in volume owing to wall collapse) and the relations among the lava level, circulatory patterns, and crater growth. Each question required different data products.

\section{Normalizing and Reducing Lidar File Size}

The 3 merged 2013 scans of the entire Halema'uma' $u$ Crater have more than 24 million topographic points each. However, not all data are necessary to address our scientific questions. The point density across the merged scans is variable, decreasing with range from the scanner positions. This results in large file sizes and increased processing times. To use the data more efficiently, the point density was normalized for processing and analysis.

Normalizing point clouds results in a merged point cloud that has an even distribution of points (that is, $x-, y$, and $z$-spacing are uniform) and which best represents the original point clouds. Because it diminishes the total number of $x$-, $y$-, and $z$-points, it allows for faster processing of large topographic datasets. To accomplish this, we applied an octree filter to the data (Xu and others, 2015). The octree filter takes a user-specified sized 3D cube and represents the original points within the cube with a single point. The user-defined dimensions of the sampled cube control the details of the resulting point cloud. The single point is the center of gravity of the average points (fig. 6). As an example, for the January 14,2013 , survey, there are $24,308,039$ points in the original merged point cloud. After applying an octree filter with cube dimensions of $0.1 \times 0.1 \times 0.1 \mathrm{~m}$, the point cloud is reduced to $17,962,417$ evenly distributed points. The resulting point cloud, with points spaced every $10 \mathrm{~cm}$ in this case, is called a polydata object. 

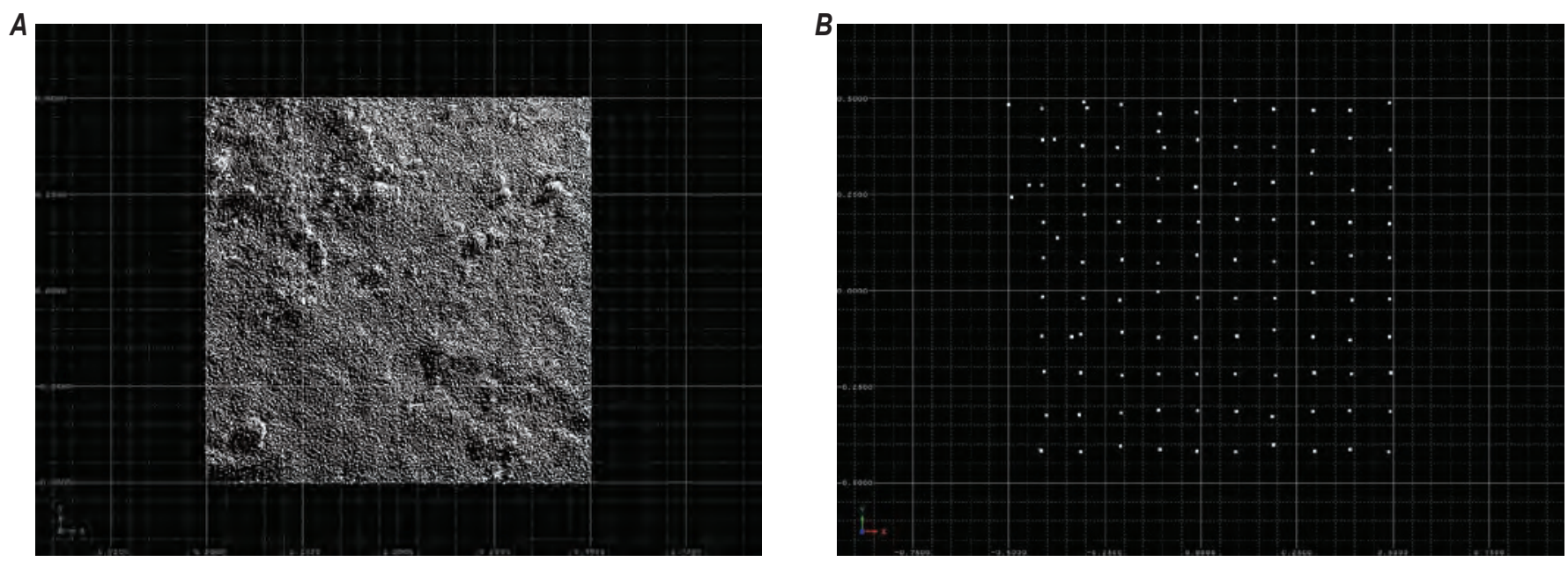

Figure 6. Images of full-density lidar point-cloud data compared to normalized data, colored by reflectance. A, A 1-square-meter area imaged from the rim of Halema'uma'u Crater, with all point measurements displayed. $B$, The same area after running a 0.1-meter octree filter. Though detail is reduced, file size is also reduced, allowing faster processing for change detection and volume calculations.

\section{Additional Lidar Data}

Additional data for this study come from two sources and were acquired from 2008 to 2011. First, the University of Hawai'i at Mānoa Pacific GPS Facility used an OPTECH TLS system to acquire scans of Halema'uma'u Crater on June 11, 2009, and February 19, 2010, and NCALM conducted a wider aerial lidar scan of Kîlauea on June 27, 2009, that included Halema'uma'u Crater and the Overlook crater. Because of the different platforms and sensors, these data have different resolutions, precisions, and accuracies but are considered high quality and comparable to the data we collected with the RIEGL TLS system. When these 3 additional datasets are combined with our 12 TLS scans, we have 15 datasets to provide quantitative comparisons of the Overlook crater geometry over a 5 -year period.

\section{Data Products Generated for this Study}

\section{Halema'uma'u Crater Data Products}

Multiple octree products were produced. The first is a 10-cm octree of the entire Halema 'uma' $u$ Crater, produced for the dates when the entire crater was surveyed. This product was used to identify static features common to all scans that could be used to align scans of different dates for topographic differencing.

\section{Overlook Crater Perimeter Data Products}

Another set of products was created to address the changing Overlook crater perimeter. To isolate the Overlook crater points, the area of interest within the lidar data was selected by utilizing a 3D spatial boundary in which all points encompassed by the Overlook crater border are differentiated from all points outside the border. Using this technique, the points within the area of interest were saved as a new polydata object (fig. 7).
Two additional products for perimeter analysis were then created from this octree subset of Overlook crater perimeter data: the full Overlook crater perimeter and a partial Overlook crater perimeter. Because of line-of-sight limitations from the scanning site closest to the Overlook crater, the full Overlook crater perimeter was not measurable for seven of our survey dates (fig. 8). For the full Overlook crater perimeter, the four following surveys were used: the June 2009 NCALM data and the January 14, 2013, August 6, 2013, and December 16, 2013 , merged datasets. The full collection of 12 terrestrial surveys provided 10 datasets for the partial Overlook crater perimeter analysis, and 2 additional datasets for measuring lava levels and wall volumes. For the three dates when the entire Halema'uma'u Crater was measured with merged TLS surveys, only the scanning site nearest the Overlook crater was utilized in constructing a partial perimeter.

We analyzed the polydata objects for the four fullperimeter datasets and selected only points slightly above and below the Overlook crater rim to provide us with coverage of only the Halema 'uma'u Crater floor and Overlook crater opening, excluding the lake surface below and airborne items (such as ejected lithic clasts and birds) above. The Halema'uma'u Crater floor dataset was further reduced by removing all points $2 \mathrm{~m}$ and farther from the Overlook crater opening, allowing us to create a small dataset that traced the Overlook crater rim. Point selection was more closely spaced in areas with increased fractures, whereas sections with a smoother edge required fewer points. Once the entire crater rim was defined, the line was closed to create a polygon. Figure 9 illustrates the process described above.

Although scanning from multiple positions around Halema'uma'u Crater and merging the data into a single TLS dataset provided full coverage of the Overlook crater perimeter, this was not always possible owing to time constraints and weather. On days where occupying multiple scan positions was not possible, we focused our efforts on scanning from the site closest to the Overlook crater. This 

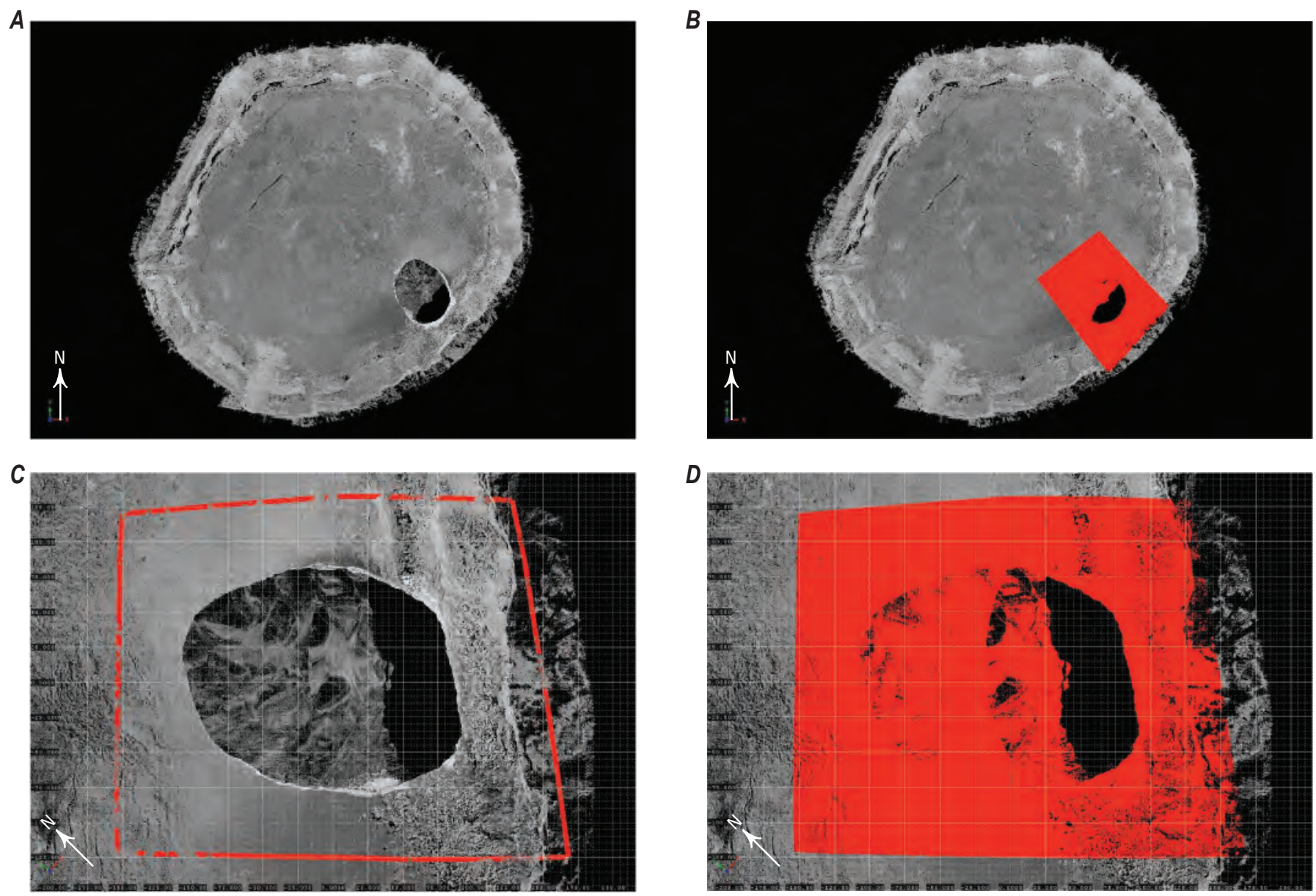

Figure 7. Nadir view images of the lidar point cloud of Halema'uma'u Crater and the Overlook crater from January 14, 2013, colored by reflectance and normalized using a 0.1-meter octree filter. $A$, Halema'uma'u Crater. $B$, Halema'uma'u Crater with the area of the point cloud in parts $C$ and $D$ highlighted in red. $C$, Overlook crater and lava lake, with the focus area outlined in red. $D$, Overlook crater and lava lake with the focus area highlighted in red.
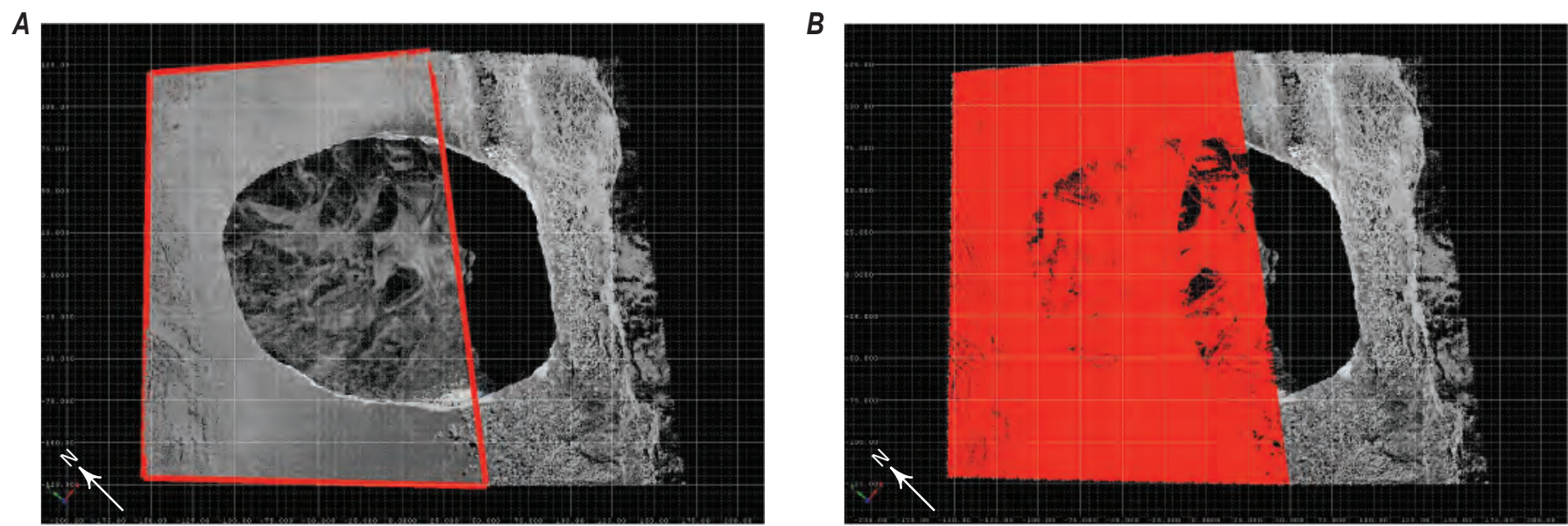

Figure 8. Nadir view images of the lidar point cloud of the Overlook crater from January 14, 2013, colored by reflectance, illustrating the selection process for the partial-wall data. Data are lacking on the right (southeastern) side of the crater because there was no line of sight from the instrument to this area. $A$, Area for unrolling outlined in red. $B$, Points used to create the partial-wall data highlighted in red. 

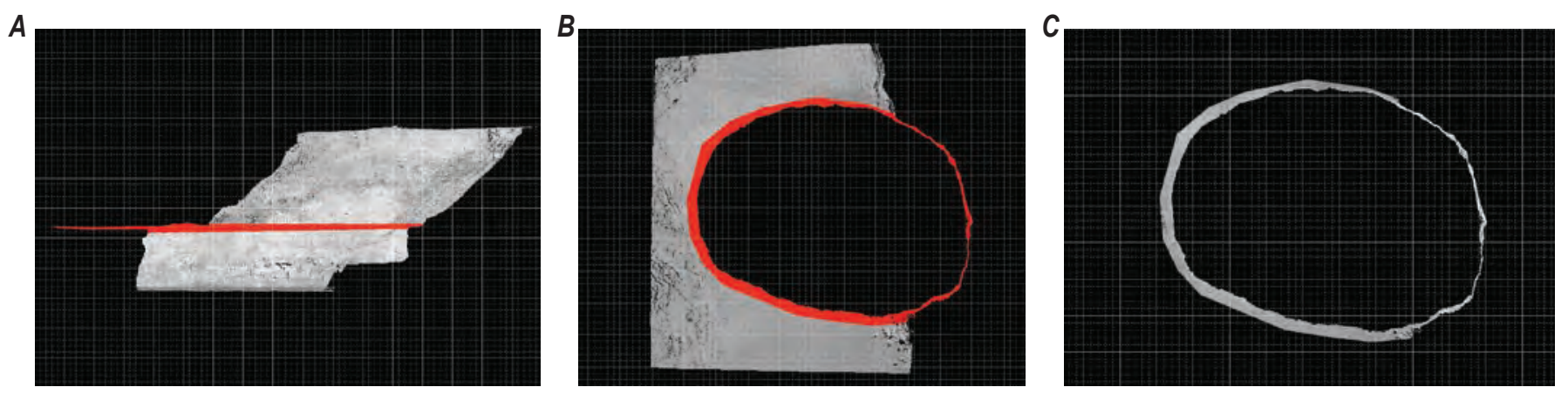

Figure 9. Images of the lidar point cloud of the Overlook crater from August 6, 2013, colored by reflectance, illustrating the selection process for the full-perimeter data. A, Points corresponding to the Halema'uma'u Crater floor and the rim of the Overlook crater were isolated. $B$, Points within a few meters of the Overlook crater rim were isolated. $C$, The resulting point cloud was used for measuring the perimeter of the crater.

site provided the most complete partial-perimeter coverage, as well as the best line of sight for imaging the Overlook crater walls and lava lake. This site was also used for the three University of Hawai'i at Mānoa Pacific GPS Facility scans that have been incorporated into this study. Unfortunately, crater geometry prevented the southeastern crater wall from being captured during scanning here. To allow for consistent comparisons between survey dates, it was necessary to select and isolate only the stretch of the Overlook crater perimeter that is present in the scans from this position (fig. 8).

\section{Lava Lake Surface Data Products}

To quantify lava levels and lake slope calculations and to investigate the relation between lake convection and Overlook crater degradation over time, we created a polydata object of only the lake surface for each survey date. These polydata objects were viewed in cross section, and points representing just the lava lake were selected. (fig. 10). The data were then converted to digital elevation models (DEMs) by connecting neighboring points through a triangular object interpolation. On some occasions, multiple surveys were run on a single

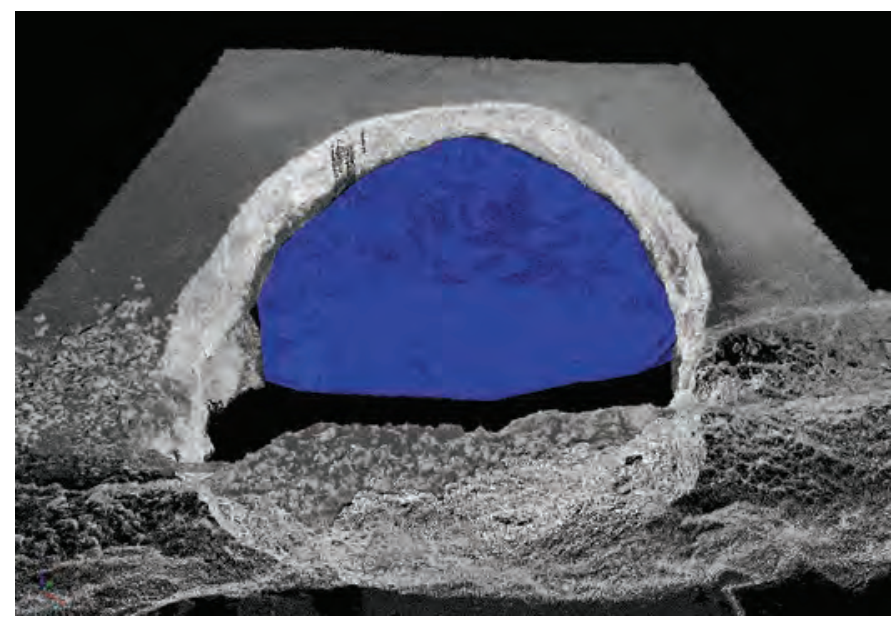

date. In these cases, lake surface elevation was measured at two locations: in the northwestern part of the lake and in the southeastern part of the lake (fig. 11). These locations correlate with the primary sites of upwelling and crustal plate foundering.

\section{Crater Wall Data Products}

Assessing the Overlook crater growth rate by measuring the perimeter opening along a 2D $x y$-plane over time is useful for estimating enlargement of the crater, but it fails to capture either the total 3D volume change within the crater or the processes responsible for this growth. It is evident within the point cloud that significant overhangs exist on the Overlook crater walls that are not evident in nadir views, indicating inherently unstable sections and substantial volume loss not captured when viewed only from above (fig. 12). Competing processes of new rock accretion on the crater walls and degradation owing to collapses within the Overlook crater can be identified by comparing volumetric measurements of the crater walls made from point clouds acquired on different dates. Therefore, it is not enough to simply calculate the net volume change within the crater between surveys, because this approach does not allow for separating areas of accretion from areas of degradation. For example, Patrick and others (2018) observed accretion of lava veneer on the Overlook crater walls near the lava lake surface that was deposited during lava-level fluctuations when this part of the crater wall was submerged and then further coated by spatter when the lava level was lower. Field observations suggest this lava veneer does not adhere strongly to the older wall rock, and slabs of material often spall off the walls when the lake level drops (Patrick and

Figure 10. Image of the lidar point cloud from January 14, 2013, colored by reflectance, viewed from approximately above the Halema'uma'u Overlook, looking down into the Overlook crater. The isolated lava lake surface is highlighted in blue. 

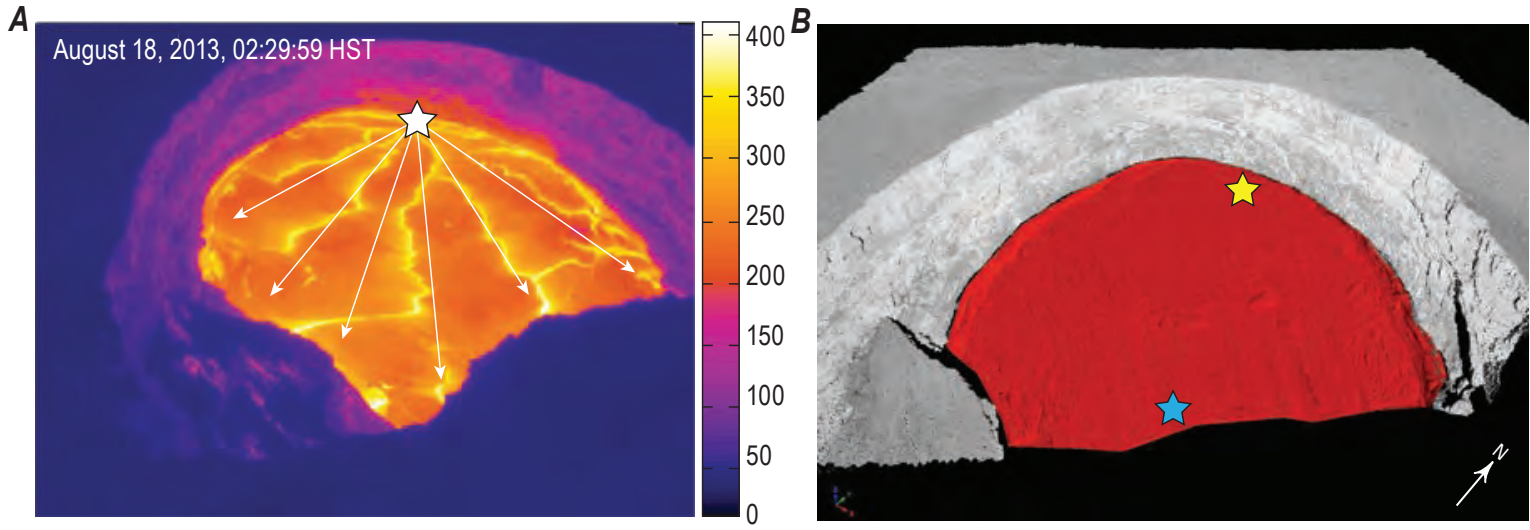

\section{EXPLANATION}

$\hat{W}$ Area of upwelling magma

Lake surface

Lake surface elevation measurement sites

$\hat{\sim}$ Northwest site

Southeast site

Figure 11. Images of the Overlook crater lava lake showing surface dynamics. $A$, Thermal infrared image taken on August 18, 2013, by the permanently installed time-lapse system on the rim of Halema'uma'u Crater. Through review of the time-lapse sequences, a consistent area of upwelling magma was identified, marked by the white star. Crustal plates formed on the surface of the lake and flowed outward toward the southern edges of the crater, where the plates sank. B, Oblique view, looking northwest, of the lidar point cloud from August 18, 2013, colored by reflectance, showing the view into the Overlook crater with the lava lake surface highlighted in red. The yellow star indicates the northwest elevation measurement site, and the blue star indicates the southeast elevation measurement site. These two stars are approximately 170 meters apart. HST, Hawaii standard time.
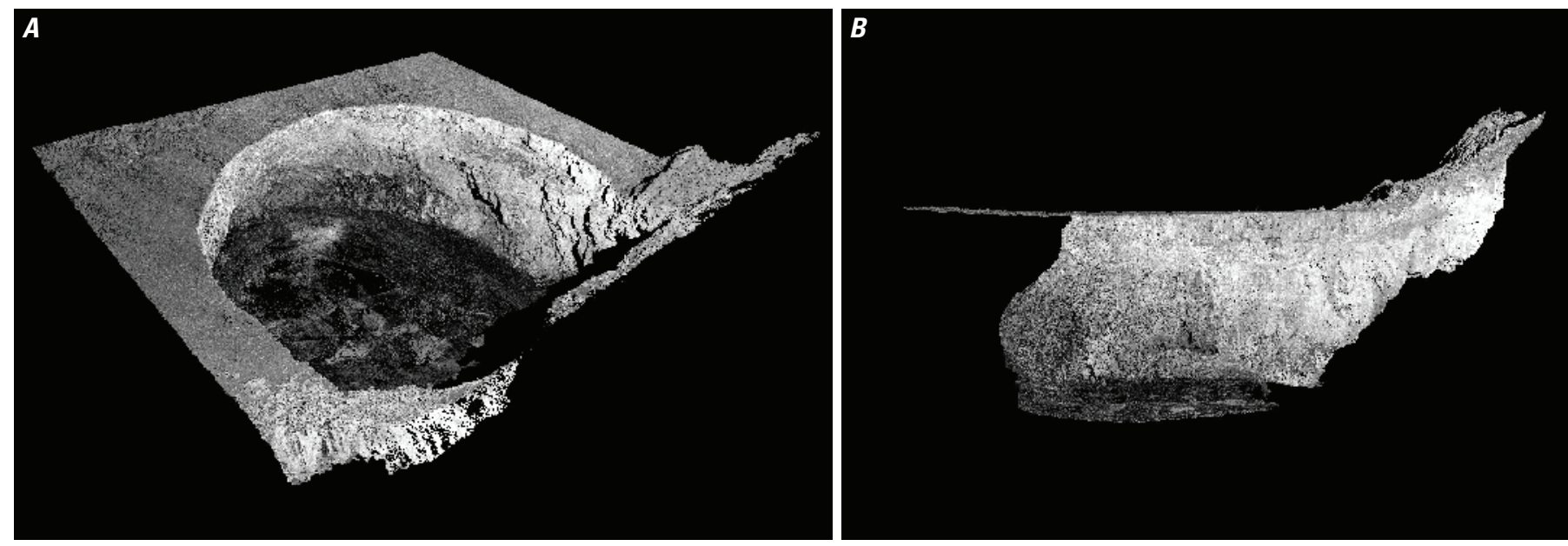

Figure 12. Images showing isometric view $(A)$ and side view $(B)$ of the lidar point cloud of the Overlook crater from February 28,2012 , colored by reflectance. The lava level on this date was the lowest of all terrestrial laser scanning (TLS) survey dates, exposing more crater wall than was seen on other dates. The left side of part $B$ (northwestern part of the crater) displays a significant overhanging section, more than 30 meters wide.

others, 2018). However, it is uncertain what happens to the wall veneer deposits when the lake level rises and recoats any remaining veneer or how long the veneer typically holds to the walls before spalling.

A comparison between successive point clouds must be performed to quantify areas of volumetric change. Available software and procedures for comparing point-cloud data for volume measurements require that the data be viewed and measured against a single reference plane. Given that the Overlook crater is somewhat cylindrical with overhanging walls, no single reference plane can be used without inducing shadowed sections. Though not an exact comparison, it is helpful to think of the issue in relation to line of sight. For example, given a static viewing position directly above the crater with a nadir view, any area below the overhanging walls of the crater will be obstructed from view (fig. 13). In a similar fashion, the algorithm used to calculate volume changes between two point-cloud surfaces will see this obstruction, and, in turn, it will calculate an inaccurate volume. We must therefore "unroll" the point cloud to view the data against a single reference plane for the entire crater.

Using CloudCompare software (Girardeau-Montaut, 2011), we selected a coordinate approximately in the center of the Overlook crater and used it as the center axis. Any points within $100 \mathrm{~m}$ of the center axis were then unrolled into a single plane. The unrolled point cloud was then rotated $90^{\circ}$ 

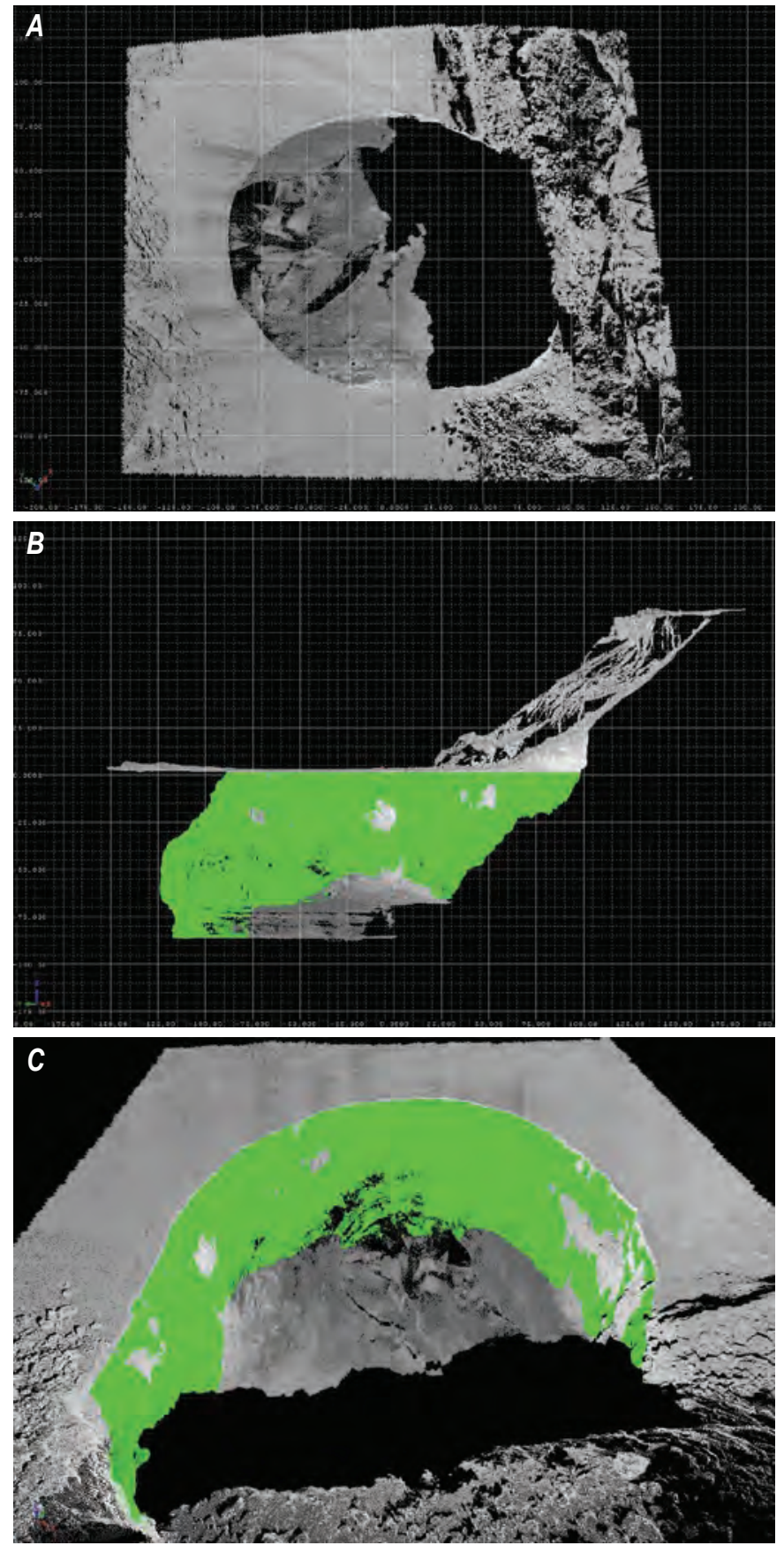

Figure 13. Images showing the lidar point cloud of the Overlook crater from February 28, 2012. Owing to overhanging walls within the Overlook crater, much of the interior wall surfaces within the crater are obstructed from nadir views. Points visible from above are colored by reflectance; points obstructed from view are colored green. $A$, Nadir view of the Overlook crater. Note that no green points are visible. $B$, Side view of the crater looking northeast. $C$, Oblique view of the Overlook crater from the rim of Halema'uma'u Crater. about the $x$-axis, so that a nadir view provides the perspective of looking directly down at the walls of the crater. This was necessary for the volume calculation procedures in RiSCAN PRO, as all calculations are made against the horizontal $x y$-plane. The unrolled and rotated point cloud was then exported as a new LAS file. For more in-depth details of the procedure in CloudCompare, see LeWinter (2014). Figure 14 tracks the importing, unrolling, and rotating process within CloudCompare.

As the lava lake surface does not have a fixed elevation, owing to the lake level fluctuations observed, it would not be appropriate to include the lake surface and material in any measurements of wall volume change. We therefore removed the lava lake surface points from each survey date (see LeWinter [2014] for details on processing techniques). This ensures that only the vertical to subvertical crater walls and the Halema'uma' $u$ Crater floor are present in volume calculations. With the lava lake surface removed, the point cloud was triangulated into a digital elevation model to have two continuous surfaces for volumetric differencing.

There are two volume calculation approaches possible: using the entire Overlook crater wall from each survey or using only the wall section above the highest extent of the lava lake surface so that the same area is compared over time. For example, the lowest lava level during our surveys was on February 28, 2012, at an elevation of $957.55 \mathrm{~m}$ above sea level (a.s.1.), and the highest measured lava level was on January 15,2013 , at an elevation of 1,014.64 $\mathrm{m}$ a.s.1.- an elevation difference of just over $57 \mathrm{~m}$. Since sections of the crater wall below 1,014.64 $\mathrm{m}$ a.s.1. were not visible within the scan data on January 15, 2013, it was not possible to include its lower elevations in a volume calculation. For this reason, two volume calculations were run: full-wall volume change and partial-wall volume change.

For the full-wall volume change calculation, successive triangulated point clouds were loaded into a viewport window within RiSCAN Pro, along with a planar object oriented in the horizontal $x y$-plane, to be used as a reference. The Calculate volume and surface area calculation was then run within RiSCAN PRO, using the earlier scan as the "base mesh" and the latter scan as the "reference mesh". The Raster Mesh calculation mode was used, which creates triangular volumes between the two meshes, and sums the volumes to produce a total volume between the meshes. Resulting volumes are separated into two categories: Fill volume and Cut volume. For this project, the Fill volume represents the volume of degradation within the Overlook crater: the volume loss between successive surveys. Cut volume represents volumes of accretion within the Overlook crater: the volume gain between successive surveys. A triangulated mesh for both Cut and Fill volumes was produced, visually representing the degradation and accretion volumes and their locations along 

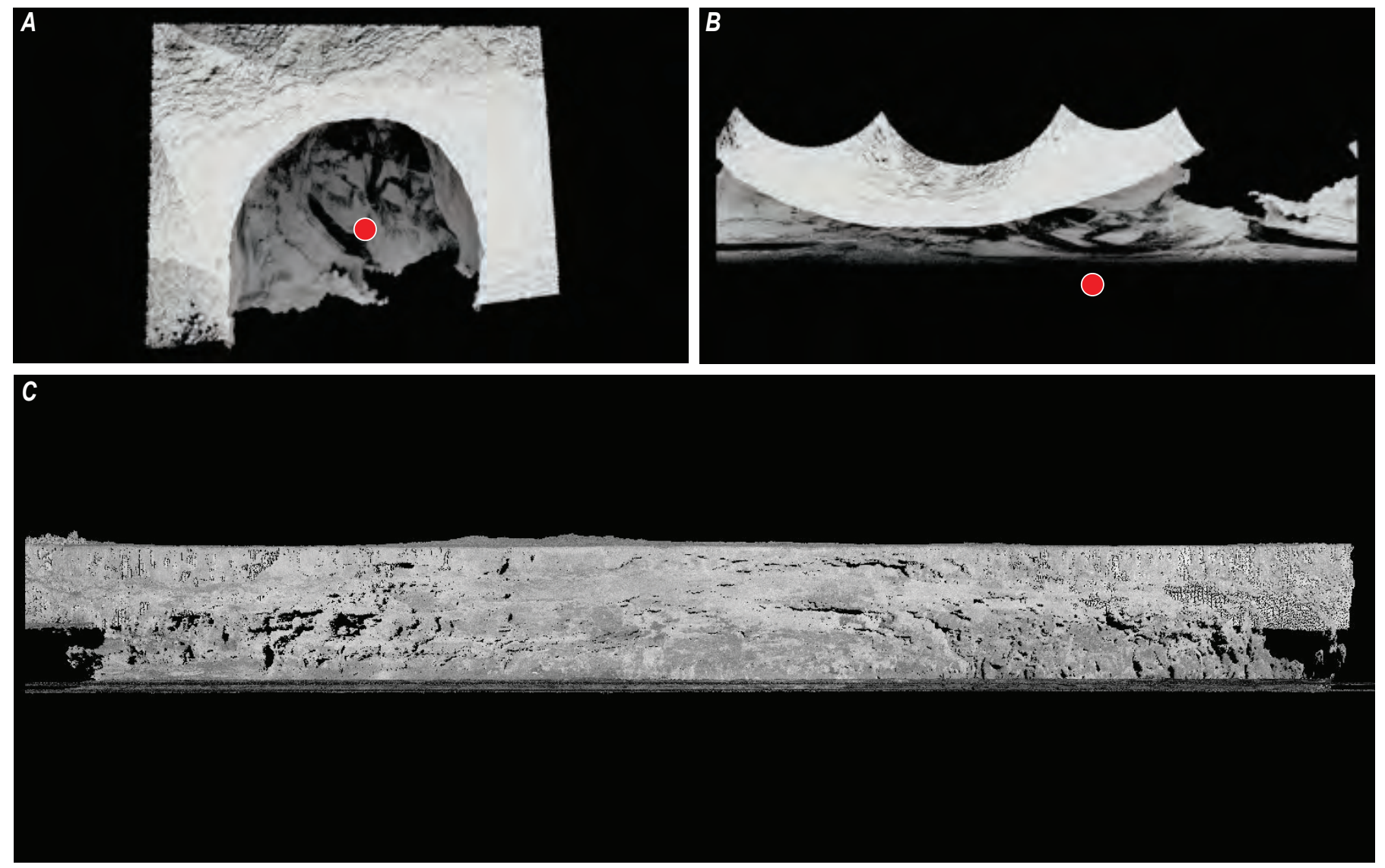

Figure 14. Images showing the partial-wall lidar point cloud of the Overlook crater illustrating the unrolling and rotation process using CloudCompare software. A, A coordinate approximately in the center of the Overlook crater (red dot) was selected and used as the center axis. $B$, Points within 100 meters of the center axis were unrolled into a single plane. $C$, The unrolled point-cloud was rotated $90^{\circ}$ about the $x$-axis, so that a nadir view provides the perspective of looking directly down at the walls of the crater. The point-cloud was then exported as a LAS file and analyzed in RiSCAN PRO.

the Overlook crater walls. See LeWinter (2014) for further details regarding the Calculate volume and surface area procedure. This was run for each successive survey pair to calculate degradation and accretion volumes. By displaying these volumes against the backdrop of the Overlook crater triangulated meshes, the areas of volume gain and loss can be tracked through time.

To run partial-wall volume change measurements, we used the unrolled and rotated point clouds described previously. Since the lake surface fluctuated between surveys, we used the survey date with the highest lava level (January $15,2013)$ to create a coverage that all other partial-wall datasets could be clipped to. All points located below the lake level were removed from the January 15, 2013, point cloud, leaving us with a new coverage of the crater walls that would be evident in all other partial-wall datasets. This ensured that all of our partial-wall datasets covered the same region of the crater walls and were not obscured by lava. Finally, the point clouds were triangulated into surface meshes, as was done for the full-wall data. This process resulted in triangulated meshes from each survey date, representing only the section of the exposed Overlook crater walls that could be differenced for volume changes.

\section{Results}

\section{Overlook Crater Perimeter Measurement and Analysis}

\section{Full Overlook Crater Perimeter and Area Measurement}

The full-perimeter lines created for each applicable dataset reveal relations between perimeter and time, showing a distinct pattern of growth (table 1). Figure 15 displays a nadir view of each full-perimeter line plotted on the same grid. The perimeter measurements show that significant growth occurred in the northwest direction along the eventual long axis of the crater, with less growth along the eventual short axis of the crater from the northeastern and southwestern crater walls. 
Table 1. Overlook crater full-perimeter length and area on survey dates that had full coverage of the crater walls.

[Complete around-the-crater surveys. $\mathrm{m}$, meter; $\mathrm{m}^{2}$, square meter]

\begin{tabular}{llcc}
\hline \multicolumn{1}{c}{ Survey date } & Survey name & Full perimeter $(\mathbf{m})$ & Area $\left(\mathbf{m}^{2}\right)$ \\
\hline June 27, 2009 & NCALM 2009 & 399.58 & $10,889.15$ \\
January 14, 2013 & 130114 & 597.47 & $25,841.92$ \\
August 6, 2013 & 130806 & 616.90 & $28,148.08$ \\
December 16, 2013 & 131216 & 627.44 & $28,553.65$ \\
\hline
\end{tabular}

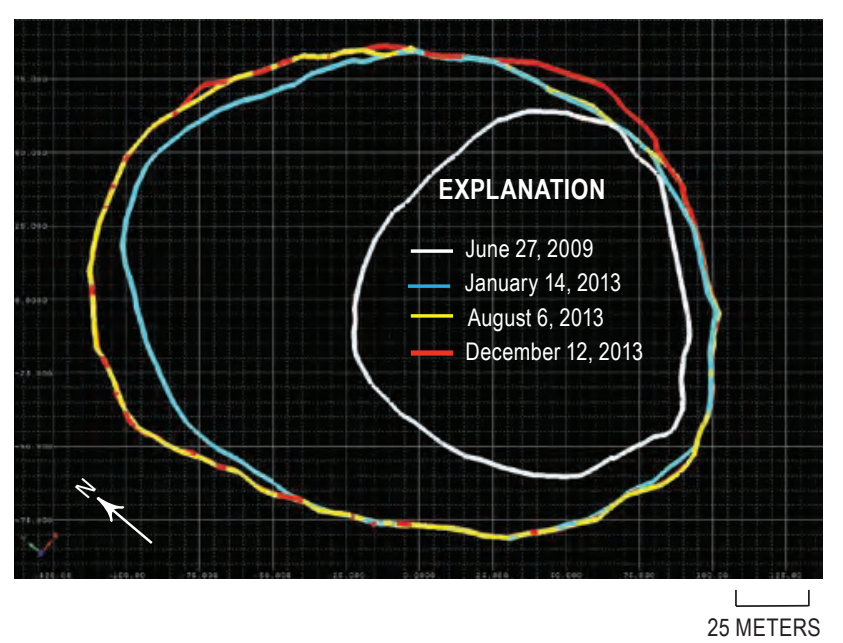

Figure 15. Plot of the Overlook crater rim using full-perimeter analysis. Perimeter lines are color coded, corresponding to survey dates. Note that areas of overlapping lines indicate little to no expansion of the crater.

The least amount of growth occurred on the southeastern side, which aligned with the steeply sloped walls of Halema'uma'u Crater. Field observations, along with careful review of thermal time-lapse imagery of the active lava lake, show that the predominant upwelling of magma occurred in the northwestern part of the crater (Patrick and others, 2016), with only short periods of alternate upwelling regimes caused by rockfall-triggered degassing events.

Figure 16 shows the perimeter length versus survey date. By plotting the full-perimeter measurements against time, it is possible to see a linear trend in the perimeter growth, albeit a weak one owing to the small number of survey dates and the wide temporal spacing between the first survey dates and the rest of the scans. Even so, this trend approximates a linear growth rate of about 52 meters per year $(\mathrm{m} / \mathrm{yr})$. The increase in the total area of the Overlook crater with time also follows a linear trend strongly controlled by the June 2009 data point, with an opening rate of 4,073 square meters per year $\left(\mathrm{m}^{2} / \mathrm{yr}\right)$ (fig. 17).

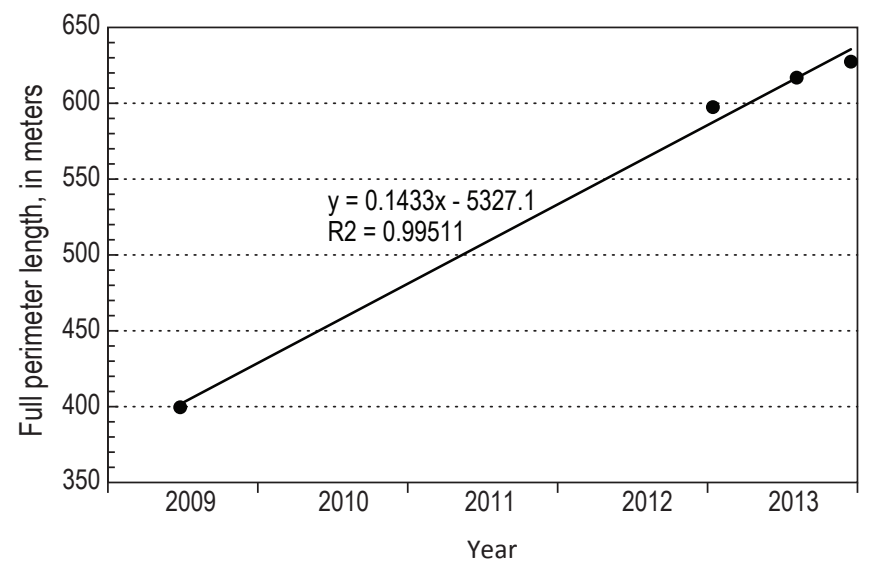

Figure 16. Plot of the Overlook crater perimeter length through time from the full-perimeter analysis. The large gap in data from June 2009 to January 2013 results in a tight-fitting linear trend, but the lack of data points limits confidence in this trend.

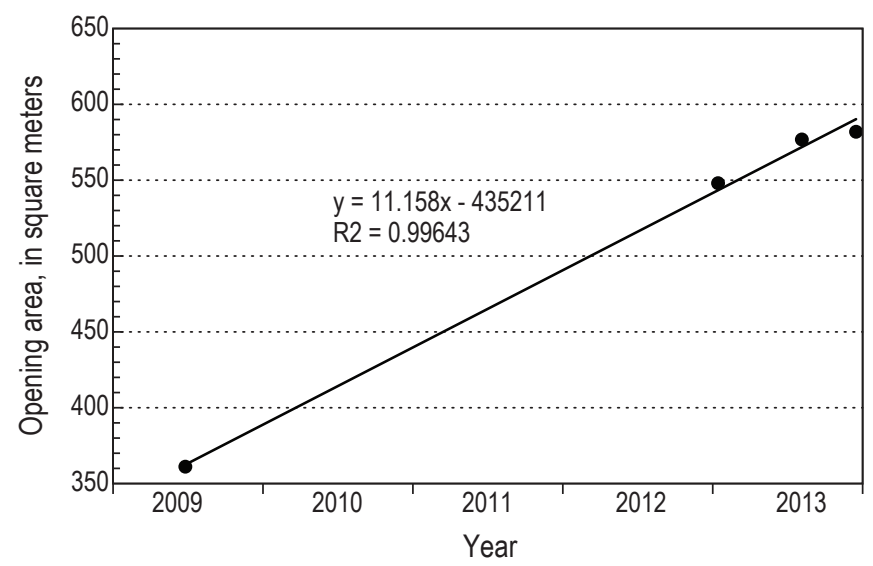

Figure 17. Plot of the Overlook crater opening area through time. Similar to the perimeter graph, the gap between June 2009 and February 2012 strongly influences the trend line, but growth appears to be consistent. The linear trendline fit to the opening-area data yields a growth rate of approximately 4,073 square meters per year. Volume calculations were done using Quick Terrain Modeler software.

\section{Partial Overlook Crater Perimeter and Area Measurement}

Several additional partial-perimeter lidar measurements help constrain the growth during the June 2009 to January 2012 gap in our full-perimeter data. A partial-perimeter line was created for each applicable TLS dataset within the area shown in figure 8 . Table 2 lists the partial-perimeter lengths and areas for each survey date, whereas figure 18 displays a nadir view of each perimeter line plotted on the same grid. These partial-perimeter measurements have a tighter temporal spacing than the full-perimeter measurements, therefore showing more detail in the growth along the northwestern part of the crater. As with the full-perimeter measurements, the 
partial-perimeter measurements are plotted against the survey date to show growth rate of the crater (fig. 19). The data suggests a growth rate for the partial perimeter of $47.49 \mathrm{~m} / \mathrm{yr}$; this value is similar to the approximately $55-\mathrm{m} / \mathrm{yr}$ perimeter growth rate determined by the full-perimeter analysis. These similar values are not surprising, given that the partialperimeter analysis only missed the southeastern part of the Overlook crater, where the Halema'uma'u Crater wall was preventing significant change.

The slight decrease in partial-perimeter length between June 11, 2009, and June 27, 2009, (table 2), a difference of $3.46 \mathrm{~m}$, can be attributed to the lower point density. Lower resolution data collected by NCALM on June 27, 2009, was compared to the TLS data collected on June 11, 2009. Visual observations of the crater revealed no substantial change in the perimeter during this interval.

Table 2. Overlook crater partial-perimeter length and area for all survey dates.

$\left[\mathrm{m}\right.$, meter; $\mathrm{m}^{2}$, square meter]

\begin{tabular}{llcr}
\hline \multicolumn{1}{c}{ Survey date } & Survey name & $\begin{array}{c}\text { Partial } \\
\text { perimeter }(\mathbf{m})\end{array}$ & Area $\left(\mathbf{m}^{2}\right)$ \\
\hline June 11, 2009 & 20090611 & 195.01 & $5,518.46$ \\
\hline June 27, 2009 & NCALM 2009 & 199.56 & $5,566.09$ \\
\hline February 19, 2010 & 100219 & 242.86 & $9,016.28$ \\
\hline February 28, 2012 & 120228 & 346.82 & $17,058.99$ \\
\hline July 10, 2012 & 120710 & 348.31 & $17,082.90$ \\
\hline January 14, 2013 & 130114 & 370.44 & $18,873.10$ \\
\hline January 15, 2013 & 130115 & 370.61 & $18,909.00$ \\
\hline January 16, 2013 & 130116 & 391.88 & $20,125.09$ \\
\hline January 17, 2013 & 130117 & 394.78 & $20,583.21$ \\
\hline August 5, 2013 & 130805 & 396.96 & $20,850.18$ \\
\hline August 6, 2013 & 130806 & 397.70 & $20,942.30$ \\
\hline December 16, 2013 & 131216 & 398.17 & $20,999.27$ \\
\hline December 17, 2013 & 131217 & 400.60 & $21,058.07$ \\
\hline
\end{tabular}

\section{Lava Lake Topography}

In addition to the 15 datasets used to study the Overlook crater rim and walls described earlier, we also collected 30 detailed lidar scans of the lava lake surface: 1 in February 2012, 2 in July 2012, 4 in January 2013, 5 in August 2013, and 18 in December 2013 (table 3). We picked a point on the northwestern part of the lava lake surface that corresponded with the typical site of upwelling, and another at the southeast sink (Patrick and others, 2016, 2018, 2019a) that corresponded with the typical site of downwelling. These two areas were separated by approximately $170 \mathrm{~m}$. By subtracting the southeastern lake surface elevation from the northwestern

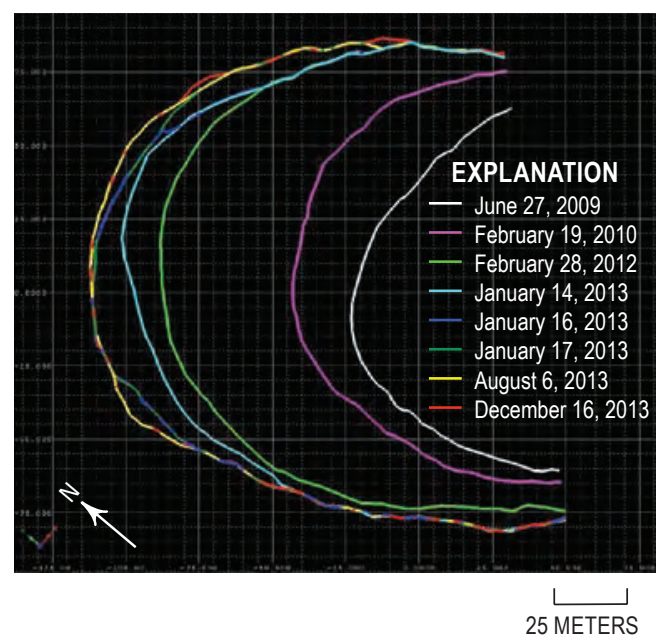

Figure 18. Plot of the Overlook crater rim using partial-perimeter analysis for 7 of the 14 terrestrial laser scanning (TLS) surveys compared to the partial perimeter of the same area derived from the June 27, 2009, NCALM airborne lidar survey (white). Several surveys listed in table 2 are not included in this figure because there was insufficient change from a temporally adjacent scan to show growth. Perimeter lines are color coded, corresponding to survey dates. Note that areas of overlapping lines indicate little to no expansion of the crater.

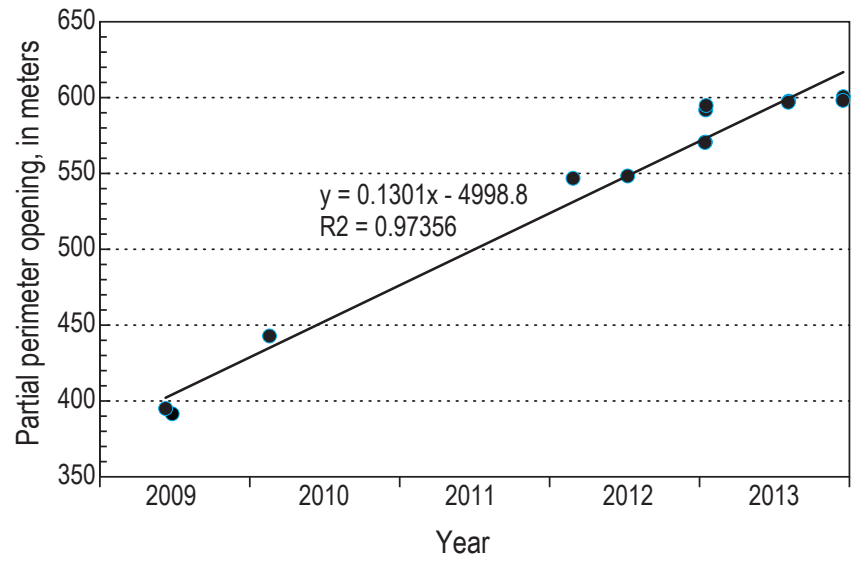

Figure 19. Plot of Overlook crater perimeter length through time from the partial-perimeter analysis.

lake surface elevation, we were able to investigate the lava lake surface slope. The upwelling site was approximately 0.3 to $0.5 \mathrm{~m}$ higher than the area of downwelling under normal convection conditions, with the greatest observed difference totaling more than $1 \mathrm{~m}$. Of note was a short period of slope reversal on December 17, 2013, between 16:00:21 and 16:14:39 Hawaii standard time (HST); the lake slope briefly switched direction during heavy outgassing and spattering, with a new area of downwelling along the west-southwest edge of the lava lake, triggered by a rockfall we observed visually. As the outgassing and spattering subsided, the lake returned to normal activity with the primary area of downwelling returning to the southeast sink. 
Table 3. Lava lake surface elevation measurements for both the northwest and southeast sites.

[Location of elevation measurement sites shown in figure 11. Elevations are above sea level (a.s.1.). The elevation difference was calculated by subtracting the southeast elevation from the northwest elevation. The lake surface is predominantly sloped from northwest to southeast, though short periods of outgassing along the west wall reversed this pattern, as highlighted in gray on December 17, 2013. HST, Hawaii standard time; NW, northwest; SE, southeast; m, meter]

\begin{tabular}{|c|c|c|c|c|}
\hline Date & Time (HST) & NW elevation (m) & SE elevation (m) & Elevation difference $(\mathrm{m})$ \\
\hline February 28, 2012 & $11: 45: 35$ & 957.78 & 957.55 & 0.23 \\
\hline July 10, 2012 & 9:09:03 & 970.18 & 969.63 & 0.55 \\
\hline July 10,2012 & $11: 27: 26$ & 969.33 & 968.85 & 0.48 \\
\hline January 14, 2013 & $12: 06: 11$ & $1,012.71$ & $1,011.64$ & 1.08 \\
\hline January 15, 2013 & $9: 57: 25$ & $1,015.20$ & $1,014.64$ & 0.56 \\
\hline January 16, 2013 & 10:08:59 & $1,010.30$ & $1,009.90$ & 0.40 \\
\hline January 17, 2013 & $9: 50: 21$ & $1,011.85$ & $1,011.21$ & 0.64 \\
\hline August 5, 2013 & $16: 07: 44$ & 994.52 & 994.25 & 0.27 \\
\hline August 6, 2013 & $9: 55: 32$ & 996.97 & 996.63 & 0.34 \\
\hline August 8, 2013 & 9:46:00 & 998.63 & 998.24 & 0.38 \\
\hline August 8, 2013 & $12: 35: 17$ & $1,005.38$ & $1,004.88$ & 0.49 \\
\hline August 9, 2013 & $13: 54: 15$ & $1,006.77$ & $1,006.50$ & 0.27 \\
\hline December 16, 2013 & 11:03:29 & 998.53 & 998.12 & 0.41 \\
\hline December 17, 2013 & 13:18:09 & 986.54 & 986.39 & 0.15 \\
\hline December 17, 2013 & $13: 30: 31$ & 986.65 & 986.19 & 0.46 \\
\hline December 17, 2013 & $13: 44: 06$ & 986.84 & 986.76 & 0.08 \\
\hline December 17, 2013 & $14: 00: 32$ & 987.44 & 987.01 & 0.43 \\
\hline December 17, 2013 & $14: 15: 32$ & 987.41 & 986.80 & 0.61 \\
\hline December 17, 2013 & $14: 30: 32$ & 987.15 & 986.95 & 0.21 \\
\hline December 17, 2013 & $14: 45: 32$ & 986.89 & 986.65 & 0.24 \\
\hline December 17, 2013 & $15: 00: 25$ & 986.48 & 986.14 & 0.34 \\
\hline December 17, 2013 & $15: 14: 08$ & 985.33 & 984.99 & 0.35 \\
\hline December 17, 2013 & $15: 30: 24$ & 984.51 & 984.33 & 0.18 \\
\hline December 17, 2013 & $15: 45: 21$ & 982.91 & 982.83 & 0.07 \\
\hline December 17, 2013 & $16: 00: 21$ & 980.76 & 981.21 & -0.44 \\
\hline December 17, 2013 & $16: 14: 39$ & 977.90 & 978.38 & -0.49 \\
\hline December 17, 2013 & $16: 34: 39$ & 978.83 & 978.48 & 0.35 \\
\hline December 17, 2013 & $16: 44: 39$ & 981.47 & 981.17 & 0.30 \\
\hline December 17, 2013 & 17:00:07 & 981.86 & 981.61 & 0.25 \\
\hline \multirow[t]{2}{*}{ December 17, 2013} & 17:15:07 & 981.68 & 981.40 & 0.29 \\
\hline & & & Average & 0.32 \\
\hline
\end{tabular}

The slope of the lava lake is apparent in elevation maps of the lava lake surface. The surface elevation is calculated by breaking the models into $1 \times 1-\mathrm{m}$ cells and calculating the mean elevation ( $z$-value) for each. This $z$-value is then used to color the cells, relative to the total elevation range within the point cloud of the lava lake surface, resulting in elevation maps that enable visualization of the lake surface topography. Figure 20 shows a selection of elevation maps next to corresponding lava level diagrams from July 10, 2012, January 17, 2013, August 8, 2013, and December 17, 2013.
Comparing the lava level and convection regime to the growth of the Overlook crater, a connection between asymmetric growth of the crater and the predominant areas of upwelling and downwelling is apparent. From the start of lidar surveys at the Overlook crater in June 2009, the crater enlarged primarily in the northwest-southeast direction, with an increase in diameter from $114.05 \mathrm{~m}$ on June 27,2009 , to $212.71 \mathrm{~m}$ on December 16, 2013, an expansion in the long axis of the crater by $98.66 \mathrm{~m}$. Conversely, in the northeastsouthwest direction, the crater increased from $124.03 \mathrm{~m}$ 

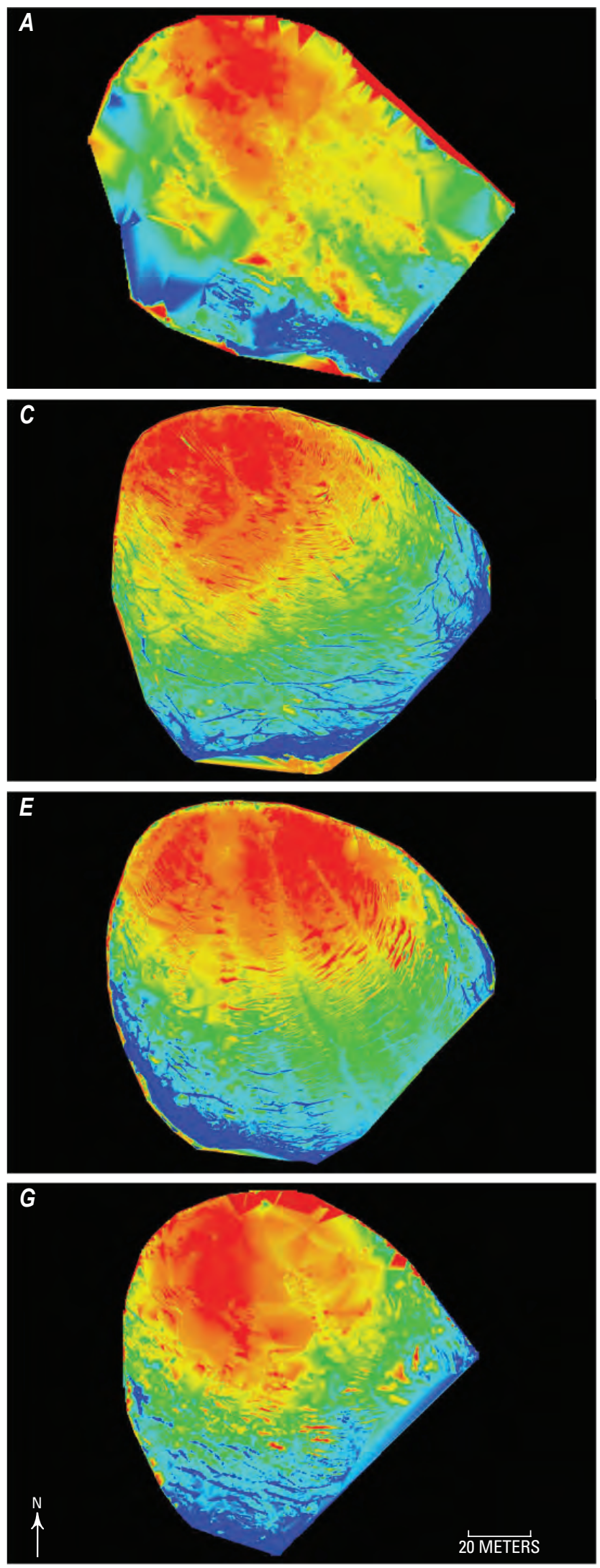
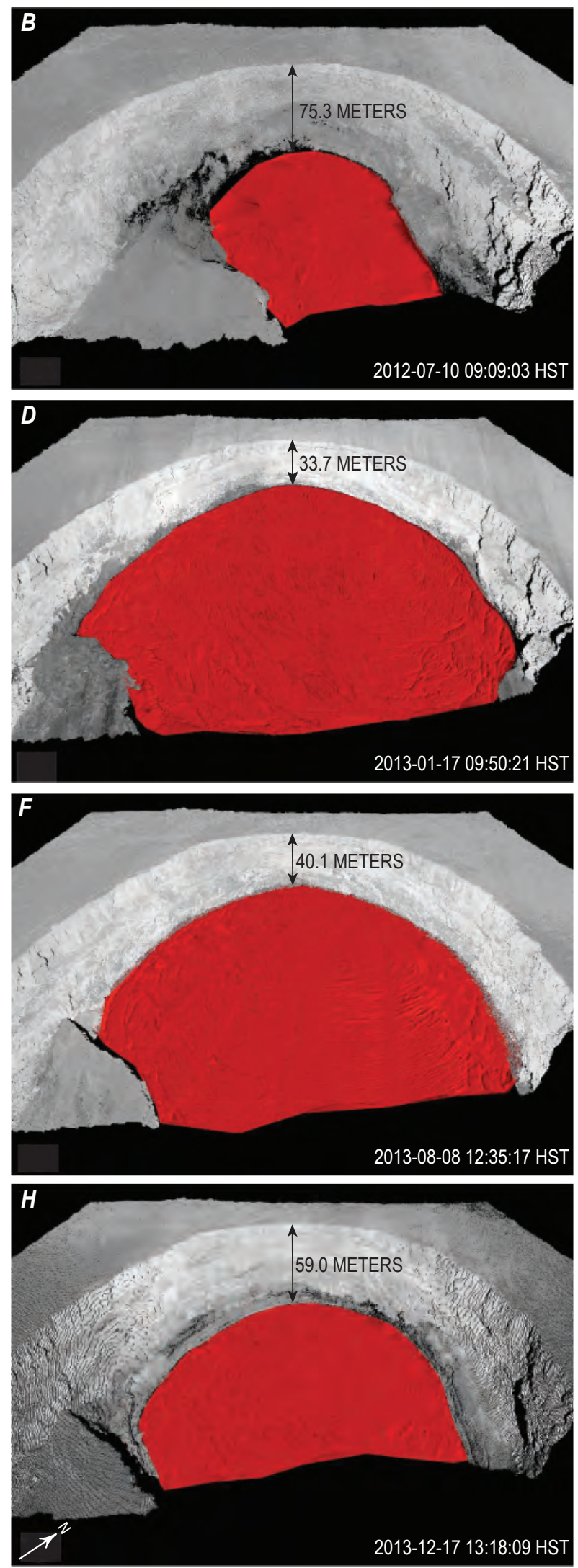

Figure 20. Images comparing the lava lake surface and height on four measurement dates. Left $(A, C, E, G)$, Elevation maps colored by height, with red showing the maximum elevation, and blue showing minimum elevation on the lake surface. Red elevations are approximately 0.6 meters higher than the lowest blue areas. The visible length of the lake surface is approximately 170 meters. Right $(B, D, F, H)$, Isometric view of the lidar point cloud looking into the Overlook crater, with the lava lake surface isolated. The distance from the Halema'uma'u Crater rim to the lava lake surface is shown. HST, Hawaii standard time. 
on June 27,2009 , to $171.68 \mathrm{~m}$ on December 16, 2013, an expansion in the short axis of the crater by only $47.65 \mathrm{~m}$. Therefore, the crater increased in diameter in the northwestsoutheast direction more than twice as much as it did in the northeast-southwest direction over this period (fig. 21).

\section{Crater Wall Measurements}

\section{Wall Volume Change-Accretion and Degradation in the Overlook Crater}

\section{Full-Wall Volume Change}

Table 4 shows the volume lost (degradation volume) and the volume gained (accretion volume) between successive scans of the Overlook crater walls, and figure 22 shows areas of accretion and degradation between selected scans. Some of the successive scans span several months, whereas others span a single day. The day-to-day scans show that the crater is constantly evolving even on a short time scale.

Based on the visual representation of accretion and degradation between individual survey periods, as well as the total accretion and degradation over the entire study
Table 4. Overlook crater full-wall degradation and accretion volumes between successive surveys.

[Date refers to the earlier survey used in the volume calculation, whereas reference date is the latter survey. Degradation volume represents the volume expansion of the Overlook crater, represented as a negative number. Accretion volume is the volume of newly deposited rock and lithic debris within the crater. $\mathrm{m}^{3}$, cubic meter]

\begin{tabular}{lllc}
\hline \multicolumn{1}{c}{ Date } & Reference date & $\begin{array}{c}\text { Degradation } \\
\text { volume }\left(\mathbf{m}^{3}\right)\end{array}$ & $\begin{array}{c}\text { Accretion } \\
\text { volume }\left(\mathbf{m}^{3}\right)\end{array}$ \\
\hline February 28, 2012 & July 10, 2012 & $-33,233.28$ & $29,132.08$ \\
July 10, 2012 & January 14, 2013 & $-89,335.59$ & 870.15 \\
January 14, 2013 & January 14, 2013 & $-1,745.49$ & $1,018.84$ \\
January 15, 2013 & January 14, 2013 & $-37,007.67$ & 332.37 \\
January 16, 2013 & January 14, 2013 & $-8,627.09$ & 451.12 \\
January 17, 2013 & August 5, 2013 & $-31,357.08$ & 378.61 \\
August 5, 2013 & August 6, 2013 & -710.65 & 244.39 \\
August 6, 2013 & August 8, 2013 & -633.87 & 472.69 \\
August 8, 2013 & August 9, 2013 & -503.99 & 441.90 \\
August 9, 2013 & December 16, 2013 & $-9,233.21$ & 681.86 \\
December 16, 2013 & December 17, 2013 & -574.03 & 818.61 \\
\hline
\end{tabular}

Figure 21. Image showing the lidar point cloud of the Overlook crater from December 16, 2013, colored by reflectance. The rim of the crater is outlined in red, and the rim of the crater on June 27,2009 , is outlined in white for comparison. The crater expanded in the northwest-southeast direction twice as much as in the northeast-southwest direction.

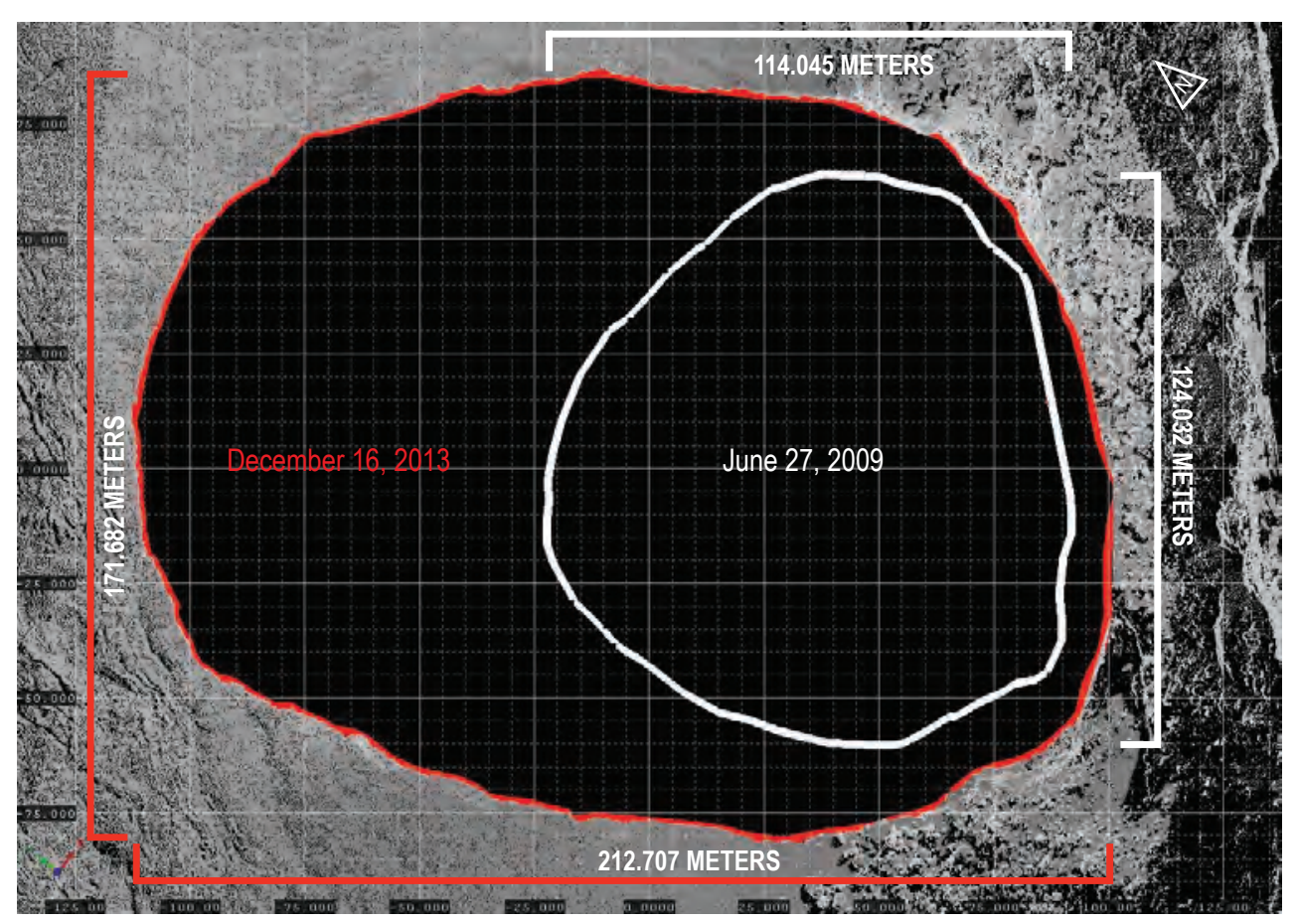

Figure 22 (page 19). Images of surface meshes derived from the partial-wall lidar point-clouds of the Overlook crater wall, colored by reflectance, showing the volumes and areas of accretion (left, green) and degradation (right, red) between successive surveys. Some survey periods are not displayed owing to minimal volumetric change. 
Febuary 28, 2012, to July 10, 2012
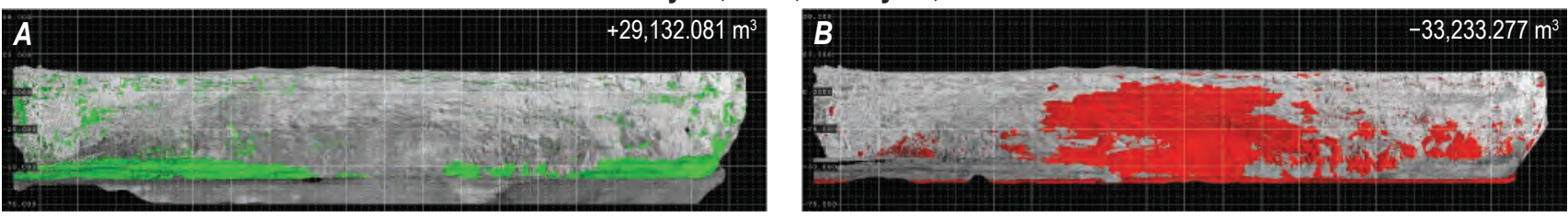

July 10, 2012, to January 14, 2013

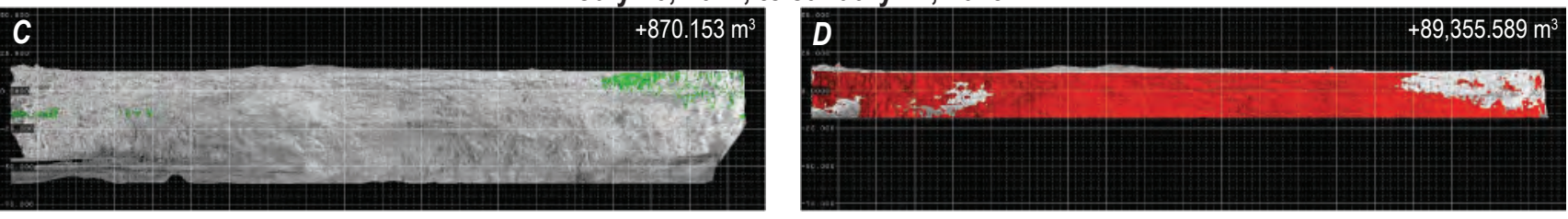

January 14, 2013, to January 15, 2013

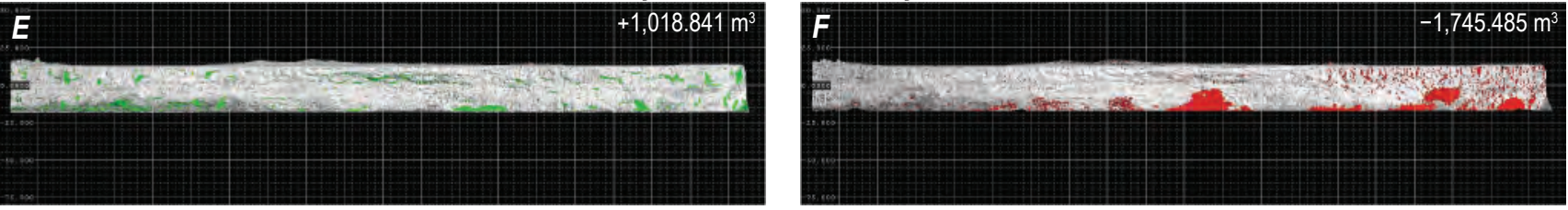

January 15, 2013, to January 16, 2013

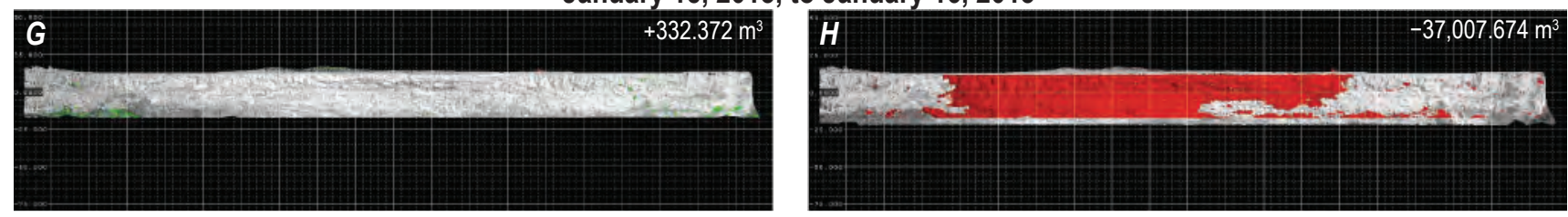

January 16, 2013, to January 17, 2013

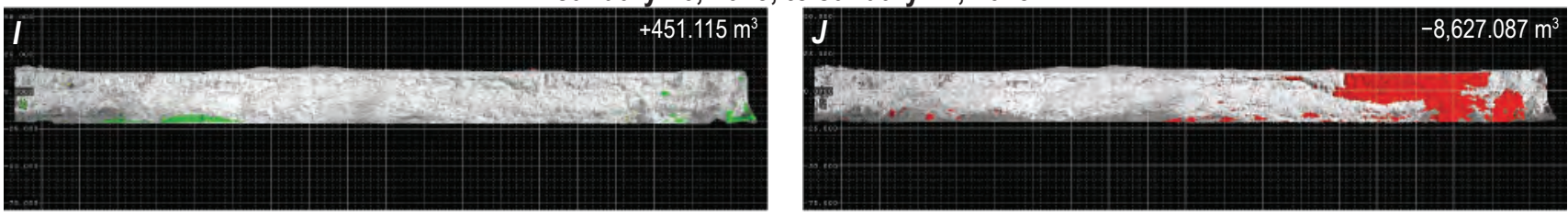

January 17, 2013, to August 5, 2013

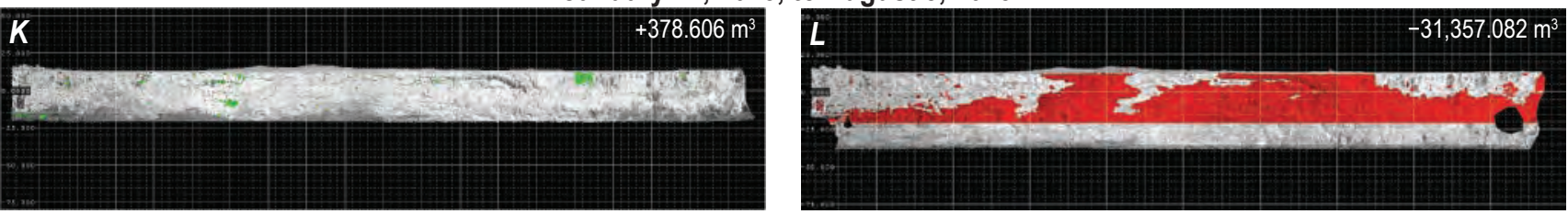

August 5, 2013, to December 16, 2013

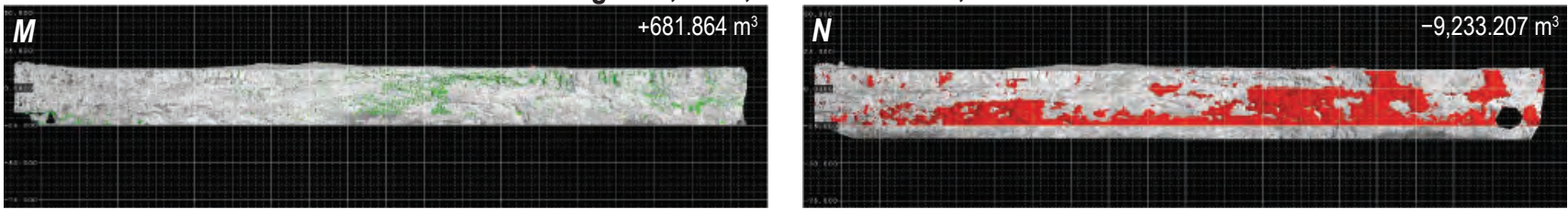

Total accretion and degradation
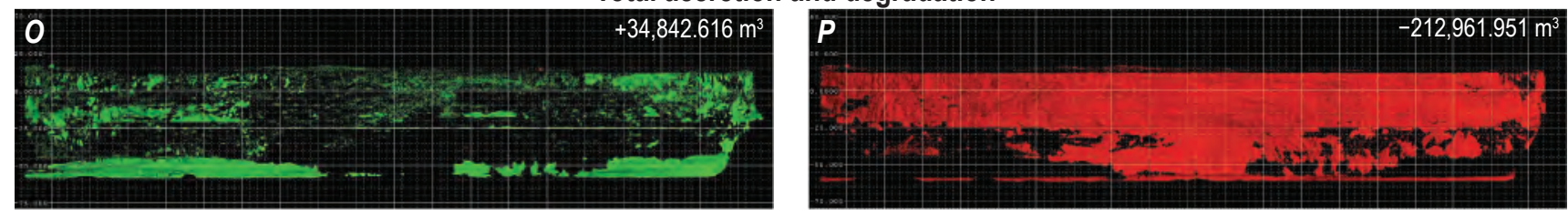

EXPLANATION

- Accretion

Degradation 
period (fig. 22), a few patterns are apparent. Degradation was widespread throughout the entire crater, whereas accretion was confined to areas directly in contact with the lava lake surface and to ledges on the Overlook crater wall where lithic and juvenile debris accumulated (Patrick and others, 2018).

We created an aspect map to illustrate this last point. Figure 23 shows the Overlook crater triangulated mesh from July 10 , 2012, colored by aspect (the weighted average orientation of a surface), represented in degrees from north. In the case of the unrolled and rotated Overlook crater mesh, north is replaced by "up". Areas of red represent ledge surfaces that face up, and which are therefore prime for collecting debris ejected from the lava lake. Figure 22 shows the total accretion volume for all surveys, with the areas of ledge surfaces shown in figure 23 .

\section{Southeastern-Wall Volume Change}

To provide insight regarding changes in the crater shape near the area of persistent downwelling in the southeast sink of the Overlook crater (Patrick and others, 2016, 2018), we processed lidar data from January 14, 2013, and December 16, 2013, the only full-crater surveys that captured the southeast sink in its mature form. The southeastern part of the Overlook crater was isolated within the point cloud and triangulated into a mesh; next, a volume calculation was run between the two point clouds, resulting in volumes for degradation and accretion. The results are consistent with previous measurements, with degradation being dominant. Again, the small amount of accretion was likely from lithic and juvenile material accumulated on ledges and wall veneer emplaced during lava level fluctuations. Most of the degradation on the southeastern wall occurred near the southeast sink, where outgassing and foundering of crustal plates was most persistent
(Patrick and others, 2016, 2018). This is consistent with the early 20th century observations and interpretations of Perret (1913a-f), who suggested that enlargement of an active lava lake and crater should occur at the areas of greatest outgassing.

\section{Discussion}

\section{Controls on Crater Growth}

Previous work sheds light on the relations between lavalake dynamics and crater growth. Oppenheimer and others (2009) estimated that as the lava lake at Mount Erebus cooled, an about 10-mm-thick frothy crust could form after being exposed at the surface for about 2 minutes. This cooled crust, having lost its volatiles, is therefore denser and flows toward the margins of the lake along an observed slope, where it sinks into the magma conduit. Perret (1913c) concluded that areas of persistent upwelling and downwelling would enhance degradation near those sites, perhaps by re-melting the walls as material rises and sinks along the crater walls, eventually forming an oblong crater. He also proposed that between the upwelling and downwelling sites, flow would allow increased accretion of cooled magma along the longer sides of the lake, creating a more elongate shape. Because the site of persistent downwelling aligns with the taller walls where the southeastern margin of the Overlook crater meets Halema'uma'u Crater, growth to the southeast has been slower than to the northwest. However, over a 1-year period, the greatest expansion along the portion of the Overlook crater that is aligned with Halema'uma' $u$ Crater is indeed nearest the site of persistent downwelling. The consistent nature of upwelling observed at the Overlook crater lava lake in the northwestern part of the

$A$

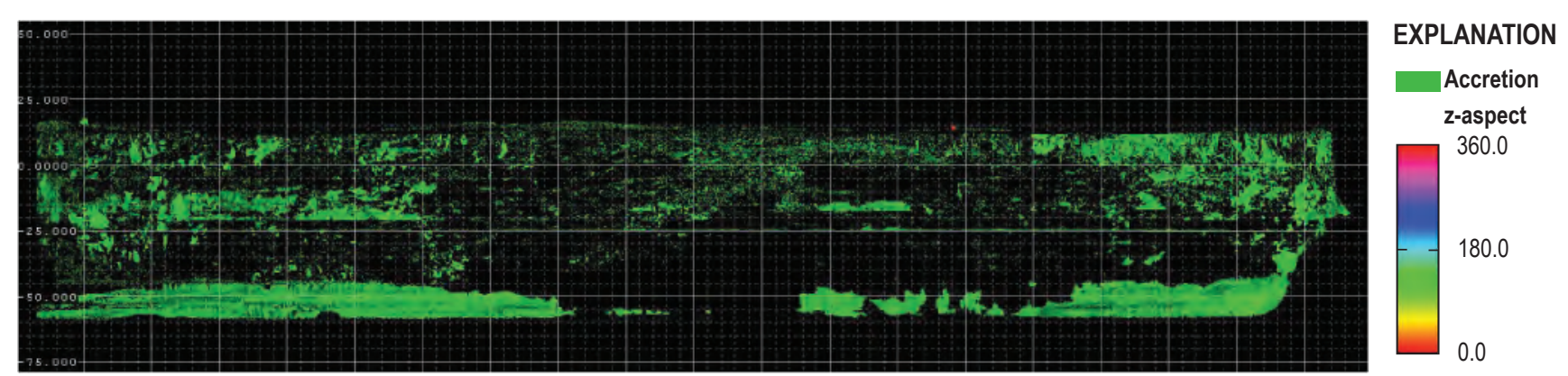

B

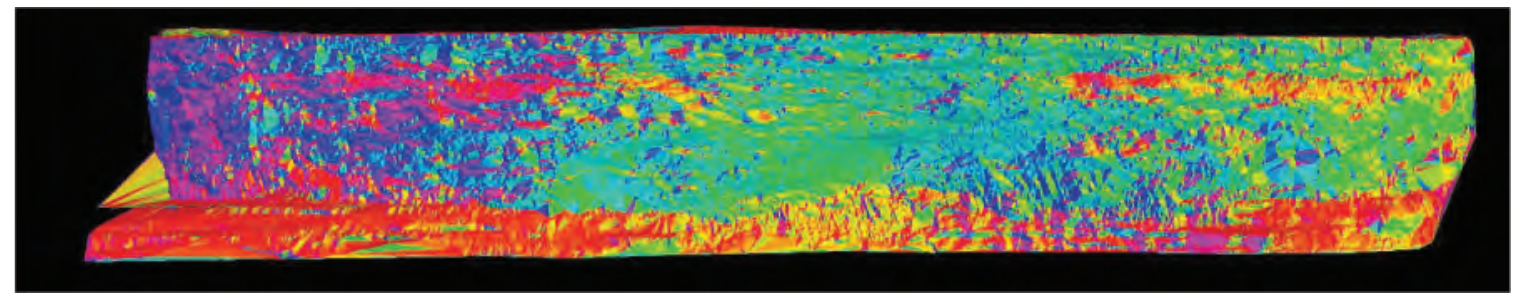

Figure 23. Images of the partial Overlook crater wall showing accretion. A, All accretion areas from the study aggregated in one view. $B$, Aspect map of the triangulated mesh from July 10, 2012. Areas colored red indicate ledge surfaces where ash and lithic debris may have accumulated, accreting material to the crater walls. 
lake, along with the observation of significant growth in that direction, is consistent with Perret's hypothesis.

Linear growth rates for both the full and partial Overlook crater perimeter were calculated at approximately 52 and $47 \mathrm{~m} / \mathrm{yr}$, respectively. We were not able to locate perimeter growth rates for similar volcanic systems in the literature, so we looked to studies of crater degradation in terrestrial and planetary settings (for example, Moore and others, 2009) and geomorphic studies of cliffs along coastlines (for example, Budetta and others, 2000) to investigate what may control the approximately linear growth pattern that is evident in our observations. Moore and others (2009) found that cliff erosion rates in the Sierra Nevada showed no correlation with topographic variables such as aspect, cliff slope angle, elevation, or length but showed a strong dependence on rock mass strength, similar to that found for coastline retreat rates (Budetta and others, 2000). This explanation may be applicable to the Overlook crater, where the crater exists within a stack of basaltic flows of similar chemical and physical character on the Halema'uma'u Crater floor, with lava-lake dynamics providing the force for degradation. Therefore, we suggest that the Overlook crater shape is controlled by persistent areas of upwelling and downwelling, and the rate of crater perimeter growth is controlled by fairly uniform rock strength.

\section{Rockfall Mechanism of Crater Growth}

Partial-perimeter measurements and thermal time-lapse imagery captured by HVO provide, respectively, tighter temporal spacing and a record of rim collapse events that reveal a general pattern of Overlook crater growth. A Mikron Infrared (IR) M7500 thermal camera was installed on the rim of Halema'uma' $u$ Crater in October 2010, and its lens was upgraded to one with a $53^{\circ}$ horizontal field of view in February 2011 (Patrick and others, 2014); the camera has an image size of $320 \times 240$ pixels and an IR range of 8 to 14 micrometers, with images being framed on the Overlook crater lava lake. At $200 \mathrm{~m}$, a single pixel represents $62 \mathrm{~cm}$ (Patrick and others, 2014). At this resolution, changes within the crater of less than approximately $1 \mathrm{~m}$ are indistinguishable. Hourly images were extracted and compiled into time-lapse video sequences that covered January 1, 2012, to December 31,2013 , spanning the entire TLS data collection effort for the survey. In reviewing these videos, 16 collapse events affecting the Overlook crater perimeter were identified, along with 1 explosive event and the collapse of a shelf within the crater (table 5). Figure 24 shows a series of images taken by the thermal camera from January 15 to 16,2013 , that spans three collapse events.

Table 5. Record of rockfall events within the Overlook crater.

[Events were observed in thermal time-lapse imagery collected by the Hawaiian Volcano Observatory between January 1, 2012, and December 31, 2013. Event description is a brief detail of the specific event within the crater; date and time indicate the beginning and end frames when the event occurred. HST, Hawaii standard time]

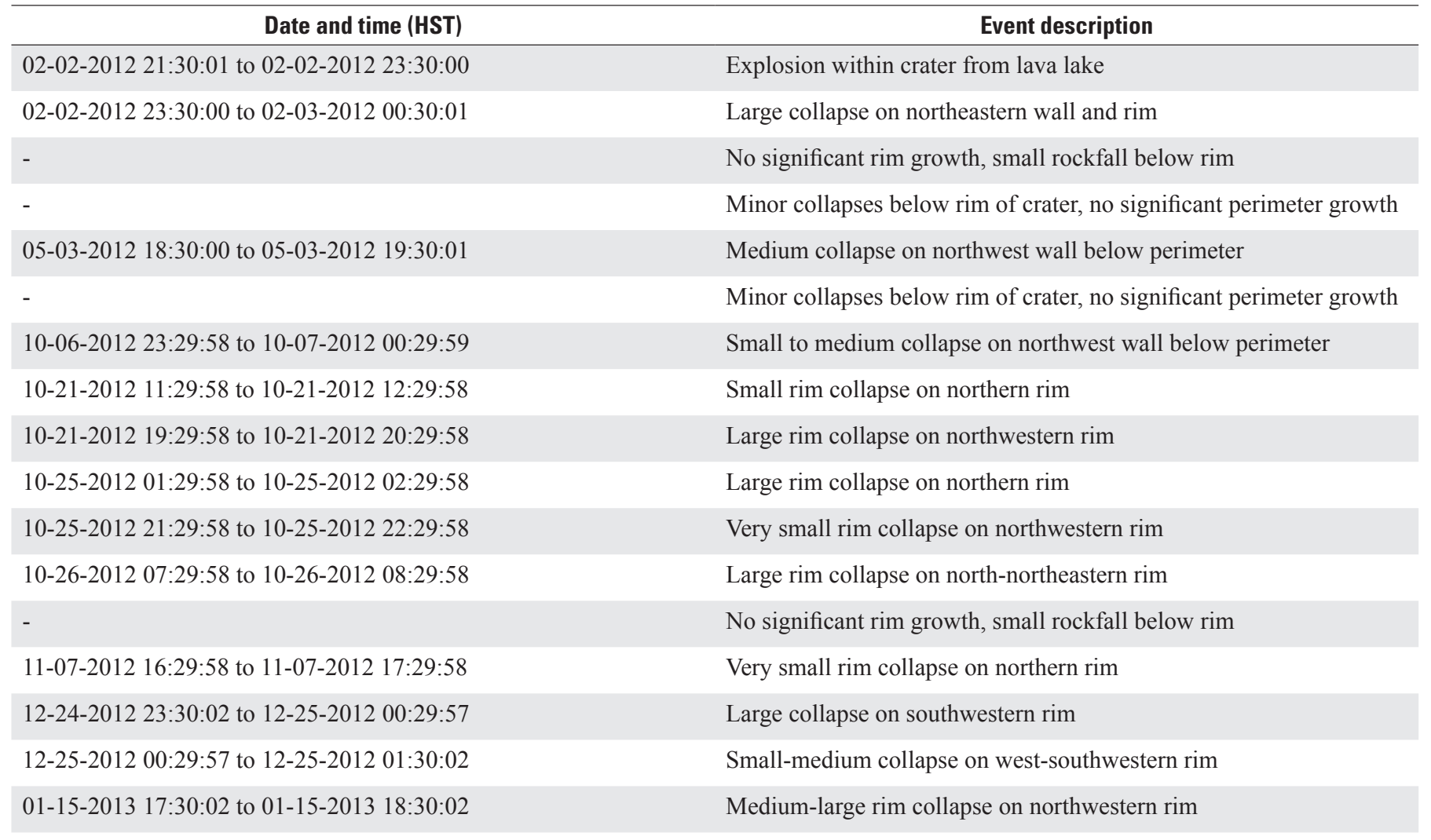


Table 5.-Continued

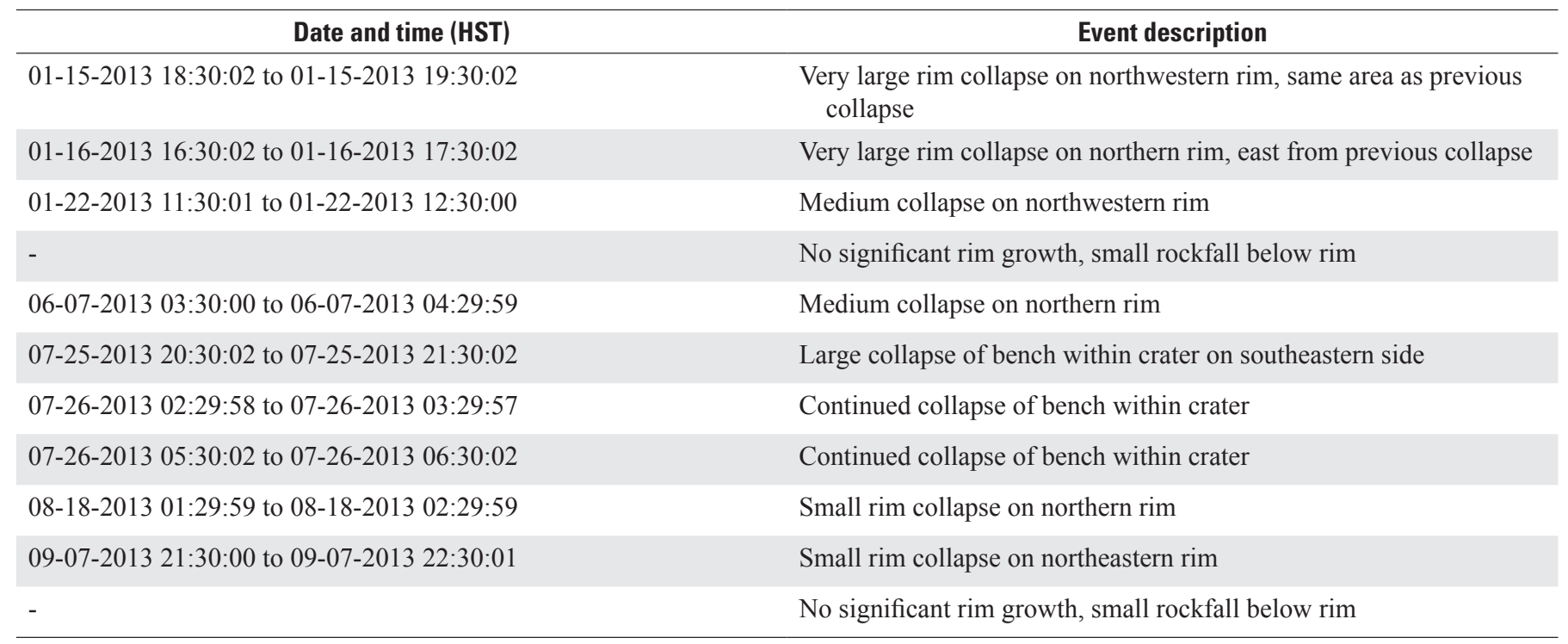
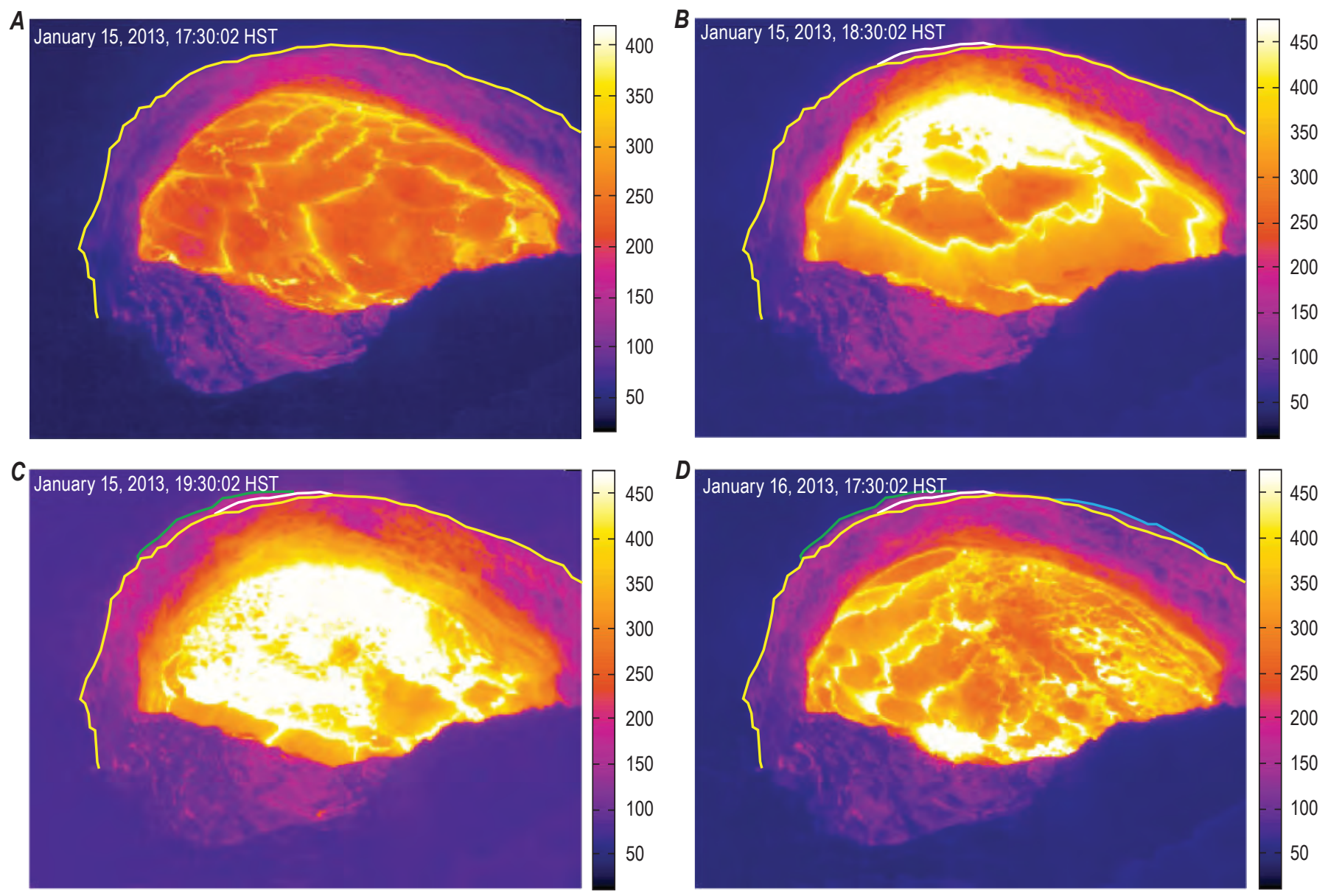

Figure 24. Series of thermal images during three consecutive Overlook crater rim collapse events from January 15 to $16,2013 . A$, January 15, 2013, at 17:30:02 Hawaii standard time (HST), with the Overlook crater rim outlined in yellow. $B$, Image captured 1 hour after image in part $A$, with the change to the rim outlined in white. $C$, Image captured 1 hour after image in part $B$, with the change to the rim outlined in green. $D$, Image captured on January 16, 2013, with the change to the rim outlined in blue. 
Table 6 shows that a relatively small number of collapse events accounted for most of the enlargement of the Overlook crater (table 6). If continued growth of the crater followed the linear trend observed (the perimeter of the crater growing at an approximate rate of $52 \mathrm{~m} / \mathrm{yr}$ ), then the area of the opening would increase at an approximate rate of $4,073 \mathrm{~m}^{2} / \mathrm{yr}$.

Table 6. Number of collapse events and the increase in area of the Overlook crater opening in periods between terrestrial laser scanning (TLS) surveys.

$\left[\mathrm{m}^{2}\right.$, square meters]

\begin{tabular}{lcc}
\hline \multicolumn{1}{c}{ Observation period } & $\begin{array}{c}\text { Area increase } \\
\left(\mathbf{m}^{2}\right)\end{array}$ & $\begin{array}{c}\text { Collapse } \\
\text { events }\end{array}$ \\
\hline February 28, 2012-January 14, 2013 & $1,814.10$ & 9 \\
\hline January 14, 2013-January 16, 2013 & $1,251.00$ & 2 \\
\hline January 16, 2013-January 17, 2013 & 458.18 & 1 \\
\hline January 17, 2013-August 6, 2013 & 341.09 & 2 \\
\hline August 6, 2014-December 16, 2013 & 74.96 & 2 \\
\hline
\end{tabular}

\section{Lava Lake Slope and Structure}

As evident from observations of thermal time-lapse imagery captured at the Overlook crater (Patrick and others, 2014), along with repeat TLS lidar data, lava level within the Overlook crater fluctuated nearly $200 \mathrm{~m}$ over the period of study. In addition, a persistent area of upwelling magma was evident in the northwestern part of the crater throughout most of the thermal time-lapse record (fig. 11) (Patrick and others, 2016). The lava-level fluctuations and the consistent magmatic upwelling area in the northwest present several questions regarding the morphometric changes within the crater. Did the sites of upwelling and subsequent sinking of crustal plates on the lake surface correlate with the lake surface slope? Did these sites correspond with areas of degradation along the crater walls? Were the lava-level fluctuations connected to periods of high degradation? Observations and analysis of the thermal time-lapse imagery and lidar data for the lava lake surface help to answer these questions. By analyzing the point measurements returned off the surface of the lava lake, a consistent northwest-tosoutheast slope was observed. Direct visual observations determined that the sites of upwelling (northwestern part of the lake) and downwelling (southeastern part of the lake) and the direction of crustal plate flow (northwest to southeast, generally) correlate with the measured slope. The lake surface bulged where the magma rose to the surface and its density was lowest, then as the crust cooled it flowed toward the area of outgassing and downflow. Short-duration outgassing in areas other than the southeastern part of the lake was triggered by rockfall, which disturbed the crustal surface, and may have altered this flow regime temporarily. Considering the measurements of the crater perimeter expansion and observations of lake convection, a pattern of maximum growth in areas of upwelling and downflow was identified.

\section{Volumetric Change of the Crater Walls}

Areas of volumetric change within the Overlook crater owing to accretion and degradation were identified and quantified between subsequent lidar surveys. Using the upper $30 \mathrm{~m}$ of the crater and excluding the southeastern wall (owing to inconsistent lidar coverage), corresponding to the wall surfaces above the lava lake that were captured in all TLS surveys, an average volumetric growth rate of 264.21 cubic meters per day was calculated. Degradation within the crater, mainly owing to rockfalls, was the predominant driver of volumetric change, with minimal accretionary contributions by the accumulation of spatter and lithic debris. Areas of accretion near the lava lake surface, caused by the adherence of spatter, only survive for hours to days. The bond between the preexisting rock of the crater wall and the veneer from spattering lava is weak, and the wall veneer spalls off shortly after the lake level drops and spattering ceases.

\section{Summary}

We used 4 lidar scans of the full Overlook crater perimeter, combined with 13 scans of the partial perimeter, to measure linear growth rates of approximately 52 and $47 \mathrm{~m} / \mathrm{yr}$, respectively, from 2009 to 2013. In addition, the Overlook crater grew from an approximately circular crater in 2009 to an oblong crater over this same period, with most growth occurring along a line between areas of persistent upwelling and downwelling. We suggest that the development of an oblong crater with a perimeter that grows linearly is best explained by a model where degradation is favored at the sites of persistent upwelling and downwelling, similar to that proposed by Perret (1913c), with linear growth enabled by a lithology that varies little with respect to rock strength.

Although the crater growth rates are generally linear over the approximately 5 -year period of study, we found that most of the Overlook crater growth occurred during a relatively small number of significant rockfall events $(\sim 16)$ over this period. Therefore, Overlook crater growth was best characterized by relatively long periods of insignificant growth interspersed with short rockfall events and associated crater enlargement.

Thirty terrestrial laser scanner datasets reveal that the lava lake had a significant slope that descended an average of about $30 \mathrm{~cm}$ across a horizontal distance of 150 to $200 \mathrm{~m}$ between the sites of dominant upwelling to downwelling. The slope of the lake and direction of crustal plate movement varied, especially when rockfalls disturbed the typical convection regime. However, these changes in slope and direction were typically of short duration (a few minutes to tens of minutes).

We calculated an average volumetric growth rate of 264.21 cubic meters per day for the upper $30 \mathrm{~m}$ of the Overlook crater wall during our study. Degradation from rockfalls within the crater was the primary cause of the volumetric change, with the collection of spatter and lithic 
debris accounting for only a minimal amount of accretion. Areas of spatter on the walls near lake surface level typically peeled away and fell back into the lake within hours to days.

We describe lidar data collection methodologies, workflows, and data products that may be applicable to other volcanologic studies. In particular, we applied a novel "unrolling technique" that allowed us to quantify changes in crater morphology that may be missed with standard topographic-differencing techniques.

High-precision lidar offers several significant advantages over structure-from-motion and other photogrammetric approaches for obtaining high-resolution topography in active volcanic settings. It is not sensitive to distortions caused by the intense heat shimmer that typically occurs in these field settings, and it can penetrate through the gas that often obscures volcanic surfaces. Although we obtained scans only during daylight hours, lidar also has the capability of working at night if finer temporal spacing of datasets is needed.

\section{References Cited}

Allard, P., Baxter, P., Halbwachs, M., and Komorowski, J.C., 2002, The January 2002 eruption of Nyiragongo volcano (Dem. Repub. Congo) and related hazards - Observations and recommendations: Paris, Final Report of the FrenchBritish Team, $35 \mathrm{p}$.

Budetta, P., Galietta, G., and Santo, A., 2000, A methodology for the study of the relation between coastal cliff erosion and the mechanical strength of soils and rock masses: Engineering Geology, v. 56. p. 243-256.

Burzynski, A.M., Anderson, S.W., Morrison, K., Patrick, M., Orr, T., and Thelen, W., 2018, Lava lake thermal pattern classification using self-organizing maps and relationships to eruption processes at Kîlauea Volcano, Hawaii, in Poland, M., Garcia, M., Camp, V., and Grunder, A., eds., Field Volcanology - A tribute to the distinguished career of Don Swanson: Geological Society of America Special Paper 538, p. 307-324, https://doi.org/10.1130/2018.2538(14).

Decker, R.W., and Christiansen, R.L., 1984, Explosive eruptions of Kīlauea Volcano, Hawaii: Geophysics Study Committee, National Research Council, 12 p.

Demant, A., Lestrade, P., Ruananza, T.L., Kampunzu, A.B., and Durieux, J., 1994, Volcanological and petrological evolution of Nyiragongo volcano, Virunga volcanic field, Zaire: Bulletin of Volcanology, v. 56, no. 1, p. 47-61.

Dzurisin, D., and Poland, M.P., 2018, Magma supply to Kīlauea Volcano, Hawai'i, from inception to nowHistorical perspective, current state of knowledge, and future challenges in Poland, M., Garcia, M., Camp, V., and Grunder, A., eds., Field Volcanology - A tribute to the distinguished career of Don Swanson: Geological Society of America Special Paper 538, p. 275-295, https://doi.org/10.1130/2018.2538(12).
Elias, T., and Sutton, A.J., 2017, Volcanic air pollution hazards in Hawaii: U.S. Geological Survey Fact Sheet 2017-3017, https://doi.org/10.3133/fs20173017.

Elias, T., Kern, C., Horton, K.A., Sutton, A.J., and Garbeil, H., 2018, Measuring $\mathrm{SO}_{2}$ emission rates at Kīlauea Volcano, Hawaii, using an array of upward-looking UV spectrometers, 2014-2017: Frontiers in Earth Science, v. 6, p. 214, https://doi.org/10.3389/feart.2018.00214.

Fowler, A., and Kadatskiy, V., 2011, Accuracy and error assessment of terrestrial, mobile and airborne LiDAR in ASPRS Annual Conference, Milwaukee, Wisc., May 1-5, 2011: American Society for Photogrammetry and Remote Sensing, 9 p.

Garcia, M.O., Caplan-Auerbach, J., De Carlo, E.H., Kurz, M.D., and Becker, N., 2006, Geology, geochemistry and earthquake history of Lō' ihi Seamount, Hawai'i: Invited Review, 80 p.

Girardeau-Montaut, D., 2011, CloudCompare-3D point cloud and mesh processing software: Technical Report, EDF Research and Development, Telecom ParisTech, accessed January 12, 2019, at http:/www.danielgm.net/cc/.

Glennie, C.L., Carter, W.E., Shrestha, R.L., and Dietrich, W.E., 2013, Geodetic imaging with airborne LiDAR - The Earth's surface revealed: Reports on Progress in Physics, v. 76, 25 p.

Kaasalainen, S., Jaakkola, A., Kaasalainen, M., Krooks, A., and Kukko, A., 2011, Analysis of incidence angle and distance effects on terrestrial laser scanner intensity-Search for correction methods: Remote Sensing, v. 3, p. 2207-2221.

LeWinter, A.L., 2014, Characterization of the Overlook crater and lava lake of Kîlauea Volcano through terrestrial laser scanning: Greeley, Colorado, University of Northern Colorado, Master's thesis, $202 \mathrm{p}$.

Longo, B., 2013, Adverse health effects associated with increased activity at Kîlauea Volcano-A repeated population-based survey: ISRN Public Health, v. 2013, article no. 475962.

Lopes, R.M.C., Gregg, T.K.P., Harris, A., Radebaugh, J., Byrne, P., Kerber, L., and Mouginis-Mark, P., 2018, Extraterrestrial lava lakes: Journal of Volcanology and Geothermal Research, v. 366, p. 74-95, https://doi.org/10.1016/ j.jvolgeores.2018.09.010.

Lundgren, P., Poland, M., Miklius, A., Orr, T., Yun, S.H., Fielding, E., Liu, Z., Tanaka, A., Szeliga, W., Hensley, S., and Owen, S., 2013, Evolution of dike opening during the March 2011 Kamoamoa fissure eruption, Kîlauea Volcano, Hawai'i: Journal of Geophysical Research, Solid Earth, v 118, no. 3, p. 897-914. 
Macdonald, G.A., 1955, Hawaiian volcanoes during 1952: U.S. Geological Survey Bulletin 1021-B, 118 p.

Mallet, C., and Bretar, F., 2009, Full-waveform topographic lidar-State-of-the-art: ISPRS Journal of Photogrammetry and Remote Sensing, v. 64, 16 p.

Mastin, L.G., Christiansen, R.L., Swanson, D.A., Stauffer, P.H., and Hendley, J.W., II, 1999, Explosive eruptions at Kīlauea Volcano, Hawai ‘i: U.S. Geological Survey Fact Sheet 132-98, 2 p.

Moore, J.R., Sanders, J.W., Dietrich, W.E., and Glaser, S.D., 2009, Influence of rock mass strength on the erosion rate of alpine cliffs: Earth Surface Processes and Landforms, v. 34, p. 1339-1352.

Okubo, C.H., and Martel, S.J., 1998, Pit crater formation on Kīlauea Volcano, Hawaii: Journal of Volcanology and Geothermal Research, v. 86, 18 p.

Oppenheimer, C., Lomakina, A.S., Kyle, P.R., Kingsbury, N.G., and Boichu, M., 2009, Pulsatory magma supply to a phonolitic lava lake: Earth and Planetary Science Letters, v. 284, p. 392-398.

Orr, T.R., Thelen, W.A., Patrick, M.R., Swanson, D.A., and Wilson, D.C., 2013, Explosive eruptions triggered by rockfalls at Kīlauea Volcano, Hawai'i: Geology, v. 41, no. 2, p. 207-210.

Orr, T., Poland, M.P., Patrick, M.R., Thelen, W.A., Sutton, A.J., Elias, T., Thornber, C.R., Parcheta, C., and Wooten, K.M., 2015, Kīlauea's 5-9 March 2011 Kamoamoa fissure eruption and its relation to $30+$ years of activity from $\mathrm{Pu}^{6} \mathrm{u}$ 'Ō'o in Carey, R., Poland, M., Cayol, V., and Weis, D., eds., Hawaiian volcanism-From source to surface: Hoboken, New Jersey, Wiley, American Geophysical Union Geophysical Monograph 208, p. 393-420.

Patrick, M.R., Orr, T., Antolik, L., Lee, L., and Kamibayashi, K., 2014, Continuous monitoring of Hawaiian volcanoes with thermal cameras: Journal of Applied Volcanology, v. 3, no. $1,19 \mathrm{p}$.

Patrick, M.R., Anderson, K.R., Poland, M.P., Orr, T.R., and Swanson, D.A., 2015, Lava lake level as a gauge of magma reservoir pressure and eruptive hazard: Geology, v. 43, no. 9, p. 831-834, https://doi.org/10.1130/G36896.1.

Patrick, M.R., Orr, T., Swanson, D.A., and Lev, E., 2016, Shallow and deep controls on lava lake surface motion at Kîlauea Volcano: Journal of Volcanology and Geothermal Research, v. 328, p. 247-261, https://doi.org/10.1016/ j.jvolgeores.2016.11.010.

Patrick, M.R., Orr, T.R., Swanson, D.A., Elias, T., and Shiro, B., 2018, Lava lake activity at the summit of Kîlauea Volcano in 2016: U.S. Geological Survey Scientific Investigations Report 2018-5008, 58 p., https://doi.org/10.3133/ $\operatorname{sir} 20185008$.
Patrick, M.R., Swanson, D.A., and Orr, T.R., 2019a, A review of controls on lava lake level-Insights from Halema'uma' $u$ Crater, Kīlauea Volcano: Bulletin of Volcanology, v. 81, https://doi.org/10.1007/s00445-019-1268-y.

Patrick, M.R., Orr, T.R., Anderson, K.R., and Swanson, D.A., 2019b, Eruptions in sync - Improved constraints on Kīlauea Volcano's hydraulic connection: Earth and Planetary Science Letters, v. 507, p. 50-61, https://doi.org/10.1016/ j.epsl.2018.11.030.

Patrick, M., Orr, T., Swanson, D., Houghton, B., Wooten, K., Desmither, L., Parcheta, C., and Fee, D., 2021, Kīlauea's 2008-2018 summit lava lake-Chronology and eruption insights, chap. A of Patrick, M., Orr, T., Swanson, D., and Houghton, B., eds., The 2008-2018 summit lava lake at Kîlauea Volcano, Hawai ‘i: U.S. Geological Survey Professional Paper 1867, 50 p., https://doi.org/10.3133/pp1867A.

Perret, F.A., 1913a, The floating islands of Halemaumau: American Journal of Science, v. 207, p. 273-282.

Perret, F.A., 1913b, The lava fountains of Kîlauea: American Journal of Science, v. 206, p. 139-148.

Perret, F.A., 1913c, The circulatory system in the Halemaumau lava lake during the summer of 1911: American Journal of Science, v. 208, p. 337-349.

Perret, F.A., 1913d, Subsidence phenomena at Kîlauea in the summer of 1911: American Journal of Science, v. 209, p. 469-476.

Perret, F.A., 1913e, Some Kīlauean formations: American Journal of Science, v. 212, p. 151-159.

Perret, F.A., 1913f, Volcanic research at Kîlauea in the summer of 1911: American Journal of Science, v. 215, p. $475-483$.

RIEGL, 2013, RiSCAN PRO version 1.7.9 Users Manual: RIEGL web page, www.riegl.com.

Tam, E., Miike, R., Labrenz, S., Sutton, A.J., Elias, T., Davis, J., Chen, Y.L., Tantisira, K., Dockery, D., and Avol, E., 2016, Volcanic air pollution over the Island of Hawai'i; Emissions, dispersal, and composition-Association with respiratory symptoms and lung function in Hawai' $i$ Island school children: Environment International, v. 92-93, p. 543-552, https://doi.org/10.1016/j.envint.2016.03.025.

Thomas, C.C., and Koonce, L., 2019, 2019 National Park visitor spending effects-Economic contributions to local communities, States, and the Nation: National Park Service, Natural Resource Report NPS/NRSS/EQD/NRR2020/2110, 52 p.

Valade, S., Ripepe, M., Giuffrida, G., Karume, K., and Tedesco, D., 2018, Dynamics of Mount Nyiragongo lava lake inferred from thermal imaging and infrasound array: Earth and Planetary Science Letters, v. 500, p. 192-204, https://doi.org/10.1016/j.epsl.2018.08.004. 
Wagner, W., Ullrich, A., Ducic, V., Melzer, T., and Studnicka, N., 2006, Gaussian decomposition and calibration of a novel small-footprint full-waveform digitising airborne laser scanner: ISPRS Journal of Photogrammetry \& Remote Sensing, v. 60, p. 100-112.

Williams, H., and McBirney, A.R., 1979, Volcanology: San Francisco, Freeman, Cooper, 397 p.

Wilson, D., Elias, T., Orr, T., Patrick, M., Sutton, J., and Swanson, D., 2008, Small explosions from new vent at Kîlauea's summit: Eos, v. 89, no. 22, p. 203.
Wright, T.L., and Klein, F.W., 2014, Two hundred years of magma transport and storage at Kīlauea Volcano, Hawai' $i$, 1790-2008: U.S. Geological Survey Professional Paper 1806, 240 p., https://doi.org/10.3133/pp1806.

Xu, H., Cheng, L., Li, M., Chen, Y., and Zhong, L., 2015, Using octrees to detect changes to buildings and trees in the urban environment from airborne LiDAR Data: Remote Sensing, v. 7, p. 9682-9704. 
Moffett Field Publishing Service Center, California Manuscript approved November 23, 2021

Edited by Regan Austin

Cover design by Cory Hurd and layout by Kimber Petersen 


\section{ख
א్}

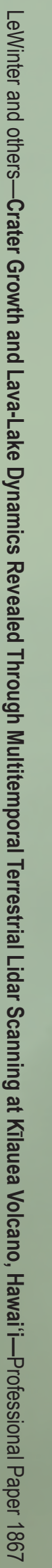

